\title{
Phenotyping for drought tolerance of crops in the genomics era
}

\author{
Roberto Tuberosa* \\ Department of Agroenvironmental Science and Technology, University of Bologna, Bologna, Italy
}

\section{Edited by:}

Antonia Okono, CGIAR Generation Challenge Programme (GCP),

Mexico

Reviewed by:

Bob Creelman, Mendel

Biotechnology, Inc., USA

Philippe Monneveux, International

Potato Center, Peru

*Correspondence:

Roberto Tuberosa, Department of Agroenvironmental Science and

Technology, Viale Fanin 44,

Bologna 40127, Italy.

e-mail: roberto.tuberosa@unibo.it
Improving crops yield under water-limited conditions is the most daunting challenge faced by breeders. To this end, accurate, relevant phenotyping plays an increasingly pivotal role for the selection of drought-resilient genotypes and, more in general, for a meaningful dissection of the quantitative genetic landscape that underscores the adaptive response of crops to drought. A major and universally recognized obstacle to a more effective translation of the results produced by drought-related studies into improved cultivars is the difficulty in properly phenotyping in a high-throughput fashion in order to identify the quantitative trait loci that govern yield and related traits across different water regimes. This review provides basic principles and a broad set of references useful for the management of phenotyping practices for the study and genetic dissection of drought tolerance and, ultimately, for the release of drought-tolerant cultivars.

Keywords: drought tolerance, phenomics, genomics, QTL, breeding, yield, phenology, modeling

\section{INTRODUCTION}

Crops are exposed to the ravages of drought in various ways and to different extents. Regrettably, global climate change will increase the occurrence and severity of drought episodes, not least due to the higher evapotranspirative demand created by rising temperatures. Altogether, these changes have already been shown to offset a significant portion of the increases in average yields that during the past three decades arose from technology, $\mathrm{CO}_{2}$ fertilization and other factors (Lobell et al., 2011). Therefore, food security in the twenty-first century will rely increasingly on the release of cultivars with improved resistance to drought conditions and with high yield stability (Swaminathan, 2005; Borlaug, 2007; Pennisi, 2008; Luo, 2010; Tester and Langridge, 2010; Reynolds et al., 2011; Serraj et al., 2011; Chapman et al., 2012).

In this challenging scenario, molecular approaches offer novel opportunities for the dissection and more targeted manipulation of the genetic and functional basis of yield under drought conditions (Forster et al., 2000; Sinclair et al., 2004; Bohnert et al., 2006; Mackill, 2006; Tuberosa and Salvi, 2006; Jenks et al., 2007; Nelson et al., 2007; Ortiz et al., 2007a; Vij and Tyagi, 2007; Leung, 2008; Xu and Crouch, 2008; Ashraf, 2010; Mittler and Blumwald, 2010; Yadav et al., 2011; Deikman et al., 2012). Additionally, the "-omics" platforms now allow for extensive mining of the transcriptome (Rabbani et al., 2003; Poroyko et al., 2007; Degenkolbe et al., 2009; Ergen and Budak, 2009; Sreenivasulu et al., 2010; Deokar et al., 2011; Hiremath et al., 2011), metabolome (Fernie and Schauer, 2009) and proteome (Timperio et al., 2008). Although, some may not consider "-omics" data as phenotypes sensu stricto, they should be treated as such, considering that they represent crucial steps that are progressively removed from genes to their ultimate phenes (Houle et al., 2010; Furbank and Tester, 2011). Not with standing the deluge of molecular data produced in the past decade, the applicable results reported so far with non-conventional approaches have not met expectations (Edmeades et al., 2004; Araus et al., 2007, 2008; Collins et al., 2008; Xu and Crouch, 2008; Heffner et al., 2009; Passioura, 2010; Sinclair, 2011), partly because the progress in high-throughput, quality phenotyping has lagged behind.

Before analyzing the factors that affect the quality of phenotypic data collected under water-limited conditions, it is important to define the nomenclature and mechanisms of crop adaptation to drought and clarify their functional basis. Most of the examples and references provided in this review refer to cereals, which, as compared to other crops, have been more extensively investigated under drought conditions. Nevertheless, most concepts presented herein are equally valid for other crops as well.

\section{DROUGHT ADAPTATION: CONCEPTS, NOMENCLATURE, AND MECHANISMS}

In agriculture, the term "drought" refers to a condition in which the amount of water available through rainfall and/or irrigation is insufficient to meet the transpiration needs of the crop. The examples presented in this review provide some general guidelines on the different mechanisms that allow plants to withstand and eventually mitigate the negative effects of water deficit. In general, a clear distinction should be made between traits that help plants to survive a severe drought stress and traits that mitigate yield losses in crops exposed to a mild or intermediate level of water stress. Modern breeding activities, including phenotyping conditions, have predominantly targeted the latter levels of stress. Although, yield remains an elusive and neglected concept in most molecular studies carried out under water-limited conditions, it is an appropriate way to gauge the overall phenotypic value of any accession. 


\section{THE FUNCTIONAL BASIS OF DROUGHT RESISTANCE}

Among the several definitions of drought resistance that have been provided during the past decades, the original one formulated by Levitt (1972) retains its validity and offers a rational approach to classify the strategies that allow plants to mitigate the negative effects of water deficit. Levitt (1972) classified the different mechanisms or strategies of drought resistance into two broad categories: dehydration avoidance and dehydration tolerance. In this respect, morpho-physiological features [e.g., deep roots, early flowering, deposition of epicuticular waxes, osmotic adjustment (OA), etc.] that enable the plant, or parts thereof, to maintain hydration are classified under dehydration avoidance. Conversely, features (e.g., remobilization of stem water-soluble carbohydrates (WSC), accumulation of molecular protectants, etc.) that allow the plant to maintain, at least partially, proper functionality in a severely dehydrated state are classified under dehydration (desiccation) tolerance. Carefully planned experiments conducted under controlled conditions allow us to separate the action of loci imparting avoidance from those providing tolerance to drought (Yue et al., 2006). Several reviews and dedicated volumes have addressed the mechanisms underlying drought resistance and the strategies that can improve yield under such conditions (Blum, 1988, 1996, 2009, 2011; Ludlow and Muchow, 1990; Ceccarelli and Grando, 1996; Passioura, 1996, 2007, 2010; Richards, 1996; Turner, 1997; Ribaut, 2006; Fischer et al., 2003; Boyer and Westgate, 2004; Chaves and Oliveira, 2004; Tuberosa, 2004; Araus et al., 2008; Kumar et al., 2008; Morison et al., 2008; Reynolds and Tuberosa, 2008; Farooq et al., 2009; Passioura and Angus, 2010; Yang et al., 2010; Sadok and Sinclair, 2011; Sinclair, 2011; Cairns et al., 2012; Mir et al., 2012).

The first step is to define the population of environments to be targeted, also identified as the TPE (target population of environments). Differences in TPE are largely determined by long-term patterns of genotype-by-environment interactions (GEI). The identification and characterization of a TPE is facilitated by the use of crop simulation models based on historic records of weather data. Simulation can describe a TPE by the frequency of occurrence of specific abiotic stresses and be based on the soil moisture profile along the crop cycle (Chapman et al., 2003). In Mediterranean environments, wheat and barley usually experience terminal drought caused by high temperatures during the grain-filling period (Araus et al., 2008). Nevertheless, within each TPE and GEI are frequently observed relating to yearly fluctuations in environmental factors (e.g., rainfall, temperature, etc.), diseases (e.g., foliar disease), and/or parasites (e.g., insects). Ideally, phenotyping for drought tolerance and yield stability should be carried out across a broad range of environments present within the TPE. During past decades, these multienvironment trials have been instrumental in increasing yield potential and also in maintaining yield stability under drought-stressed conditions in temperate maize (Tollenaar and Wu, 1999; Duvick, 2005; Tollenaar and Lee, 2006) as well as in other crops (Lafitte et al., 2006; Crossa et al., 2007; Acuna et al., 2008). In a few cases, they have also allowed for the identification of major QTLs consistently affecting yield across a range of water availability (Bernier et al., 2007, 2009; Maccaferri et al., 2008; Venuprasad et al., 2009a,b, 2012; Vikram et al., 2011; Dixit et al., 2012; Ghimire et al., 2012).

\section{WATER-USE EFFICIENCY AND GRAIN YIELD UNDER WATER-LIMITED CONDITIONS}

Water-use efficiency (WUE) is the amount of dry matter produced [grain yield (GY) in the case of grain crops when considering seasonal WUE] per unit of water lost through evapotranspiration. A classical formula that highlights the critical role of WUE in determining GY in crops grown in water-limited conditions was suggested by Passioura (1977):

$$
\mathrm{GY}=\mathrm{W} \times \mathrm{WUE} \times \mathrm{HI}
$$

where $\mathrm{W}$ is the total amount of water transpired by the crop and evaporated from the field and HI is the harvest index, i.e., the ratio between GY and total biomass. Salekdeh et al. (2009) identify phenotyping protocols that address each formula's factors, describe their key features and illustrate their integration with different molecular approaches. When using this formula, one should consider the possible interdependence of these variables, with the result that selection for improving WUE in order to increase GY may be partially counterbalanced by a reduction in the amount of water extracted from the soil. In fact, a number of traits influence both $\mathrm{W}$ and WUE.

The most important factor is matching the phenological development pattern of the crop and the seasonal rainfall pattern (Richards, 1996; Turner, 1997; Araus et al., 2003; Morison et al., 2008; Soltani and Sinclair, 2012). Early vigor potentially improves both $\mathrm{W}$ and WUE, while deep roots and/or osmoregulation under appropriate conditions increase water extraction from the soil (Blum, 1988, 2011; Ludlow and Muchow, 1990; Richards, 2006; Reynolds and Tuberosa, 2008; Sadok and Sinclair, 2011). However, we should keep in mind that farmers eventually harvest grain and not WUE, which means that a lower WUE may actually be desirable when WUE is negatively associated with GY, as is well-known in cereals differing in their intrinsic WUE (Blum, 2005, 2006, 2009). Therefore, WUE should not be equated to drought tolerance. The best example is provided by a population of related progeny such as recombinant inbred lines (RILs) that differ in their capacity to extract soil moisture due to differences in root depth, and hence greater capacity to access moisture stored in deeper soil layers. Because, WUE is higher in genotypes characterized by low stomatal conductance, often resulting from a lower water status, the genotypes that are more wasteful (i.e., with a lower WUE) and able to extract more water from the soil (Merah, 2001; Rebetzke et al., 2002; Blum, 2006, 2009, 2011), whilst maintaining higher stomatal conductance, will have higher yield. Conversely, under conditions of limited soil moisture, low WUE resulting from excessive evapotranspiration will not allow sustained accumulation of dry matter and its partitioning to reproductive organs (Monneveux and Ribaut, 2006; Richards, 2006; Tambussi et al., 2007; Barnabas et al., 2008; Sinclair et al., 2008). This finding introduces an essential concept for interpreting cause-effect relationships between morphophysiological traits and GY under drought conditions: the sign and magnitude of this relationship at the whole-plant or QTL level are 
not universal and can change widely according to the dynamics (i.e., frequency and timing) and intensity of the drought episode/s (Collins et al., 2008; Sinclair et al., 2010; Tardieu, 2012).

An alternative formula to address properly the factors influencing WUE in crops grown under water-limited conditions has been proposed by Richards (1991):

$$
\text { WUE (biomass) }=\mathrm{TE} /\left(1+E_{s} / T\right)
$$

where TE is the transpiration efficiency (above ground dry weight/transpired water), $E_{\mathrm{s}}$ is the water lost by evaporation from the soil surface and $T$ is water lost through transpiration by the crop. Analysis of the variables in this formula provides a useful framework for identifying the agronomic and breeding strategies, and hence phenotyping targets, most suitable for optimizing WUE and maximizing yield in environments that differ in rainfall distribution during the crop cycle.

At the leaf level, "intrinsic WUE" indicates the ratio of the instantaneous rates of $\mathrm{CO}_{2}$ assimilation and stomatal transpiration. Condon et al. (2002) discussed the factors influencing intrinsic WUE and how an increased intrinsic WUE can be achieved through either lower stomatal conductance, higher photosynthetic capacity, or both. The same authors caution about the possible penalties in terms of yield through manipulation of each variable. They conclude that to achieve more widespread gains in cereal yield derived from greater intrinsic WUE, it is necessary to decouple intrinsic WUE and low crop growth rate. In practical terms, WUE becomes more important when crops grow predominantly on stored soil moisture (Condon et al., 2002), as reflected by the release of wheat cultivars Drysdale and Rees (Richards, 2006), specifically selected for target areas where wheat is grown under such conditions.

\section{WHICH TRAITS SHOULD BE TARGETED?}

The morphophysiological traits and the corresponding QTLs that affect yield in drought conditions can be categorized as constitutive (i.e., also expressed under well-watered conditions) or drought-responsive (i.e., expressed only under pronounced water shortage; Lafitte and Edmeades, 1995; Blum, 2006). While drought-responsive traits/QTLs usually affect yield only under rather severe drought conditions, constitutive traits/QTLs can affect yield at low and intermediate levels of drought stress as well. The response of QTLs for drought-adaptive traits (e.g., accumulation of osmolytes, relocation of WSC, etc.) to drought is probably due to regulation of the expression of the underlying structural genes in response to signaling cues such as abscisic acid (ABA) accumulation (Bray, 2002) that are reinforced by cellular dehydration. Under appropriate soil moisture conditions, the presence of QTLs for traits usually classified as constitutive but difficult to measure (e.g., root depth) can be revealed by the collocation of QTLs for traits indicative of the water status of the plant such as ABA concentration, stomatal conductance, canopy temperature depression (CTD), etc., (Lebreton et al., 1995; Tuberosa et al., 2002b; Reynolds et al., 2009, 2011). Experimental evidence indicates that the progress achieved by breeders during the last century can mainly be accounted for by changes in constitutive traits that affect dehydration avoidance rather than drought-responsive traits (Blum, 2005, 2006, 2011). In this respect, emphasis is increasingly being placed on phenotyping traits that constitutively enhance yield per se (Blum, 2009; Passioura, 2010), rather than on characteristics that enhance plant survival under extreme drought (Bartels et al., 2006), in view of a possible negative trade-off under less severe circumstances (Blum, 1996, 2005, 2006; Passioura, 2002, 2007, 2010; Sinclair, 2011).

The traits to be considered as potential selection targets for improving yield under water-limited conditions must be genetically (i.e., causally) correlated with yield, and should have a greater heritability than yield itself (Blum, 1988, 2011; Monneveux and Ribaut, 2006). Additional desirable features are the presence of sufficient genetic variability and lack of yield penalties under favorable conditions. Ideally, measurement of the target trait should be non-destructive, rapid, accurate, and inexpensive. It should also be possible to measure the trait using a small number of plants and without lengthy procedures to calibrate sensors to individual plants. Finally, rather than reporting on short-term features at the cellular level, the nature of the secondary trait should be integrative across the growing cycle, or part thereof, and relate to higher levels of functional organization (e.g., the canopy level rather than the single leaf), thereby providing information on the long-term ecophysiological performance of the crop. General information and examples are now provided on a number of traits that have been investigated for their influence on drought resistance and/or WUE.

\section{EARLY VIGOR}

Early vigor under conditions of low evapotranspiration may allow annual crops to optimize WUE and limit the loss of water due to direct evaporation from the soil surface. This leaves more stored water available for later developmental stages when soil moisture becomes progressively exhausted and increasingly limiting for yield (Slafer et al., 2005; Richards, 2006; Rebetzke et al., 2007; Richards et al., 2007). Early establishment also reduces the occurrence of inhibition of stomatal conductance as a consequence of root-borne signaling such as from ABA through the xylem flow (Davies et al., 2000; Ren et al., 2007) caused by shallow and superficial roots (Blum, 1996; Giuliani et al., 2005). As a trade-off, excessively vigorous canopy development may cause early depletion of soil moisture. The optimal degree of vigor will thus depend on the environmental characteristics of the TPE. Early vigor has been exploited to improve WUE and yield in wheat (Asseng et al., 2003; Richards, 2006; Rebetzke et al., 2007). QTLs for the growth rate of wheat seedlings (Spielmeyer et al., 2007) are being targeted at CSIRO (Commonwealth Scientific and Industrial Research Organization, Australia) ${ }^{1}$.

\section{ROOT ARCHITECTURE}

Roots exhibit an astounding level of morphological plasticity in response to soil physical conditions (Passioura, 1983; Bengough et al., 2006; Gerald et al., 2006; Ito et al., 2006; Kato et al., 2007; Lynch, 2007; Forde, 2009; Siopongco et al., 2009), a peculiarity that allows plants to adapt better to the chemical and physical properties of the soil, particularly under drought conditions

\footnotetext{
${ }^{1} \mathrm{http} / /$ www.csiro.au/files/files/p2ki.pdf
} 
(Bacon et al., 2002; Yu et al., 2007). The concept of root ideotype should be elaborated only after gaining a detailed understanding of: (1) the factors that limit the availability of soil moisture to the crop; and (2) the metabolic cost sustained by the plant to develop and maintain a more vigorous root system. Notably, recurrent selection for increased GY in drought-stressed tropical maize was associated with a decrease in root mass (Bolaños and Edmeades, 1993). Accordingly, the effects of root size and architecture on final yield will depend on the distribution of soil moisture and the level of competition for water resources within the plant community (King et al., 2009). Therefore, when additional stored moisture is available in deeper soil layers, selection for faster growing and deeper roots could enhance water harvest and help stabilize yield under drought conditions.

The importance of a deep and vigorous root system for higher yield has been recognized in bean (Mohamed et al., 2002), soybean (Sadok and Sinclair, 2011), chickpea (Varshney et al., 2011), lettuce (Johnson et al., 2000), maize (Tuberosa et al., 2003, 2007b, 2011b; Hammer et al., 2009; Landi et al., 2010; Hund et al., 2011), barley (Forster et al., 2005), wheat (Manschadi et al., 2006, 2010; Wasson et al., 2012), and especially, in rainfed rice (Nguyen et al., 1997; Price and Tomos, 1997; Ali et al., 2000; Babu et al., 2003; Courtois et al., 2003, 2009; Steele et al., 2006, 2007; Kamoshita et al., 2008; Witcombe et al., 2008; Bernier et al., 2009; Henry et al., 2011). However, other experiments in rice have shown a lack of correlation between root features and drought resistance (Pantuwan et al., 2002; Subashri et al., 2009).

The main drawback to the study of root features and their use as selection criteria relates to the difficulty of phenotyping field-grown plants (Richards, 2008). A number of techniques allow for the estimation of root mass and its distribution in the soil profile. These techniques require different amounts of labor and plot destruction for sample collection. The fastest but most destructive technique measures the vertical pulling strength required to uproot the plant, as a proxy for root mass and architecture (Lebreton et al., 1995; Sanguineti et al., 1998; Landi et al., 2002). Recently, a high-throughput, albeit equally destructive approach also known as "shovelomics," has been deployed to investigate several root architectural features in field-grown maize (Trachsel et al., 2011). Other less destructive but much more time-consuming techniques such as excavation and coring methods have also been used to estimate root mass and distribution (Nissen et al., 2008).

Minirhizotrons provide a non-destructive, in situ method for directly viewing and studying fine roots (Johnson et al., 2001; Smit and Groenwold, 2005). Tube installation is critical, and steps must be taken to ensure good soil/tube contact without compacting the soil. Tube installation causes some degree of soil disturbance and has the potential to create artifacts in root data collection and analysis, resulting in biased values. Therefore, a waiting period of a few months between tube installation and image collection is recommended to allow roots to recolonize the space around the tubes and to permit nutrients to return to predisturbance levels (Johnson et al., 2001). The frequency of image collection depends upon the root parameters being measured or calculated, and the time and resources available for collecting images and extracting data.
In maize, a fast non-destructive method to estimate root mass has relied on the use of a hand-held capacitance meter (van Beem et al., 1998; McBride et al., 2008). The accuracy of this method was tested by comparing the results with direct measurements taken on uprooted plants grown in the greenhouse and in the field. The significant correlation ( $r$ from 0.56 to 0.73 ) between the methods suggests the feasibility of using capacitance meters for routine, non-destructive observations repeated over time. Despite this possibility, the method has not been widely applied.

Heterogeneity in soil structure and composition hinders the acquisition of accurate values for root features in field-grown plants. As an alternative to root phenotyping in field experiments, a number of studies have measured roots in plants grown under controlled conditions (Arihara and Crosbie, 1982; Price et al., 1997a, 2002b,c; Landi et al., 1998, 2001a; Tuberosa et al., 2002b; de Dorlodot et al., 2005, 2007; Kimurto et al., 2005; Zhu et al., 2006, 2011; Hochholdinger and Tuberosa, 2009; Zaman-Allah et al., 2011a; Ren et al., 2012). This allows more rapid and accurate analysis of root features. A major shortcoming of these studies is the unnatural environment in which the roots grow, suggesting great caution in extrapolating the results to field-grown plants. In maize, a significant, albeit weak, positive association has been reported between seminal root traits in hydroponics and root pulling resistance in the field (Landi et al., 2001a; Tuberosa et al., 2002b). A reasonable compromise to avoid both the unnatural conditions present in hydroponics and/or aeroponics and the difficulty of studying roots in the field is offered by growing plants in pots, columns and/or observation chambers filled with soil (Azhiri-Sigari et al., 2000; Wade et al., 2000; Zaman-Allah et al., 2011a). Pot experiments also allow for a precise measurement of the amount of water provided to each plant, hence water use and WUE (Price et al., 2002b), and to estimate the capacity of roots to penetrate a wax layer of high mechanical impedance mimicking a soil hardpan, often the main constraint that limits access of roots to soil moisture in deeper soil layers (Cairns et al., 2004; Nhan et al., 2006; Acuna et al., 2007). In rice, an enhanced capacity to penetrate a soil hardpan is considered an essential feature for the development of deeper roots under rainfed lowland conditions (Fukai and Cooper, 1995) and is a key factor in drought adaptation in areas where water supply is limited (Siopongco et al., 2009).

Gel- or soil-filled chambers, soil sacs, pouches, paper rolls, $\mathrm{X}$-ray microtomography, and magnetic resonance imaging (MRI) have also been used to investigate bi- and tri-dimensional root architecture (Bengough et al., 2004; Sanguineti et al., 2007; Hargreaves et al., 2009; Norton and Price, 2009; Ruta et al., 2010; Tracy et al., 2010; Bovina et al., 2011; Clark et al., 2011; Rascher et al., 2011; Singh et al., 2011; Alhosein et al., 2012; De Smet et al., 2012; Hamada et al., 2012; Mace et al., 2012). These experiments are particularly suited to the discovery of QTLs that are prevalently expressed in a constitutive fashion and which, as such, are more likely to influence root architectural features (e.g., root angle) across different soil conditions.

\section{FLOWERING TIME}

Flowering time is recognized as the most critical factor to optimize adaptation, hence yield, in environments differing in water 
availability and distribution during the growing season (Richards, 2006). Positive associations between plasticity of yield and flowering time across different levels of water availability have been reported in different crops (Sadras et al., 2009). Therefore, in addition to phenology per se (i.e., mean time to a phenological stage), plasticity of phenological development merits consideration as a distinct trait influencing crop adaptation and the outcome of any QTL experiment where the effects of phenology on yield are not duly recognized and accounted for (Pinto et al., 2010; Sabadin et al., 2012).

Many studies have investigated the genetic basis of flowering time, reflecting the economic importance of this trait. In annual crops, the genetic basis of flowering time is more complex in temperate species (e.g., barley, wheat, rye, etc.) as compared to tropical species (e.g., rice, sorghum, maize, etc.), due to the presence in the former group of verbalization genes influencing flowering time in response to low temperatures. In cereals, the switch from the vegetative to the reproductive phase is controlled, according to the species, by several genes responsive to verbalization and/or daylength as well as by loci for earliness per se (Salvi et al., 2002, 2007, 2011; Distelfeld et al., 2009).

In maize, a valuable selection target for improving drought resistance is provided by the anthesis-silking interval (ASI), a trait of intermediate heritability that is usually negatively correlated with GY under drought conditions (Bolaños and Edmeades, 1996; Monneveux and Ribaut, 2006). Because ASI can be phenotyped quite easily and effectively under the right experimental conditions, substantial breeding efforts have targeted this trait through conventional breeding (Chapman and Edmeades, 1999) or, once QTLs have been identified (Ribaut et al., 1996; Li et al., 2003a; Hao et al., 2008), with marker-assisted selection (MAS) (Ribaut et al., 2004; Ribaut and Ragot, 2007). The negative association reported between the effects of QTLs that have been shown to influence both leaf elongation and ASI suggests turgor maintenance as a possible common mechanism accounting for the correlation (Welcker et al., 2007).

\section{CARBON ISOTOPE DISCRIMINATION}

Carbon isotope discrimination $\left(\Delta^{13} \mathrm{C}\right)$ measures the ratio of stable carbon isotopes $\left({ }^{13} \mathrm{C} /{ }^{12} \mathrm{C}\right)$ in the plant dry matter compared to the ratio in the atmosphere (Condon et al., 1990). Because of differences in leaf anatomy and the mechanisms of carbon fixation in species with the $\mathrm{C}_{3}$ or $\mathrm{C}_{4}$ pathway, studies on $\Delta^{13} \mathrm{C}$ have wider implications for $\mathrm{C}_{3}$ species where the variation in $\Delta^{13} \mathrm{C}$ is larger than in $\mathrm{C}_{4}$ species and has a greater impact on crop yield (Condon et al., 1990, 2006). Commonly, but not always (Turner et al., 2007), $\Delta^{13} \mathrm{C}$ is negatively associated with WUE over the period of dry mass accumulation (Condon et al., 1990, 2004; Araus et al., 2002; Rebetzke et al., 2002; Xu et al., 2007; Royo et al., 2008).

Under drought stress, $\Delta^{13} \mathrm{C}$ is a good predictor of stomatal conductance (Condon et al., 2002) and WUE in different crops (Turner, 1997; Tambussi et al., 2007). A number of studies conducted in bread wheat under varying conditions of water availability have shown that the correlation between $\Delta^{13} \mathrm{C}$ and final GY varies from positive, when ample water is available to the crop, to negative in drought conditions, with no correlation at all in intermediate conditions (Condon et al., 1993, 2004). These results can be interpreted based on the influence of both stomatal conductance and photosynthetic activity on $\Delta^{13} \mathrm{C}$, and on the fact that biomass production is limited in wet years by a lower stomatal conductance-an advantage under drought conditions (Turner, 1997). $\Delta^{13} \mathrm{C}$ measured in grains correlates positively with growth cycle duration (Araus et al., 1997) and negatively with leaf temperature (Richards et al., 2002). Therefore, the relationship between $\Delta^{13} \mathrm{C}$ and GY depends on the environmental conditions, the phenology of the crop and the plant organ (e.g., leaf or grain) from which the samples are collected (Araus et al., 1997; Merah et al., 2001; Condon et al., 2004).

High genetic variation for grain $\Delta{ }^{13} \mathrm{C}$ has been reported in $\mathrm{C}_{3}$ species (Turner, 1997; Chen et al., 2012), with high heritability (e.g., from 0.76 to 0.85 in durum wheat; Merah et al., 2001) and a low GEI (Richards, 1996; Rebetzke et al., 2008a). For these characteristics, $\Delta^{13} \mathrm{C}$ is an attractive breeding target for improving WUE and yield, while the high cost required to measure each sample makes it an interesting candidate for MAS.

\section{STOMATAL CONDUCTANCE}

Stomatal conductance plays a pivotal role in regulating the water balance of the plant and determining $\Delta^{13} \mathrm{C}$ and WUE (Condon et al., 2002; Richards et al., 2002, 2007; Sinclair et al., 2008, 2010). A retrospective study conducted by Fischer et al. (1998) on a historical series of successful bread wheat cultivars released by CIMMYT from 1962 to 1988 showed a strong positive correlation between stomatal conductance and GY $(r=0.94$; Fischer et al., 1998), indicating the possibility of raising the yield potential, hence the amount of water used by the crop, through an indirect selection for stomatal conductance and/or leaf temperature.

Given the laborious nature of measuring stomatal conductance, identifying the corresponding QTLs would allow for the implementation of MAS. In fact, it is difficult to accurately measure stomatal conductance in a reasonably large number of plants while properly accounting for the fluctuation in the main environmental factors known to affect stomatal conductance during the day (wind, solar radiation, humidity, etc.). A number of studies have reported QTLs for stomatal conductance (Lebreton et al., 1995; Price et al., 1997b, 2002a; Sanguineti et al., 1999; Ulloa et al., 2000; Takai et al., 2006; Khowaja and Price, 2008).

A more attractive and integrative way to indirectly monitor stomatal conductance through an extended time-period is based on the measurement of the natural oxygen isotope composition $\left(\mathrm{d}^{18} \mathrm{O}\right)$ in leaf and grain materials (Barbour et al., 2000; Ferrio et al., 2007). Compared with stomatal conductance, measuring $\mathrm{d}^{18} \mathrm{O}$ in plant material offers four advantages: (1) it provides an integrated measure of stomatal conductance and leaf temperature over the period that the analyzed tissue was formed; (2) it avoids a number of experimental problems typical of measuring stomatal conductance; (3) it allows for the collection of a large number of samples, and (4) requires very little labor in the field. In the historical series of CIMMYT wheat cultivars tested under irrigated conditions (see above), leaf $\mathrm{d}^{18} \mathrm{O}$ was strongly correlated with stomatal conductance ( $r=-0.93$; Barbour et al., 2000). In this case, GY was more strongly correlated with leaf $\mathrm{d}^{18} \mathrm{O}$ $(r=-0.90)$ as compared to leaf $\mathrm{d}^{13} \mathrm{C}(r=-0.71)$. However, the 
authors caution that $\mathrm{d}^{18} \mathrm{O}$ is a questionable yield predictor when stomatal conductance and GY are not strongly correlated.

\section{CANOPY TEMPERATURE DEPRESSION}

CTD as measured by thermal imaging is the difference in temperature between the canopy surface and the surrounding air. CTD is a highly integrating trait resulting from the effects of several biochemical and morphophysiological features acting at the root, stomata, leaf, and canopy levels. In the field, genotypes with a cooler canopy temperature under drought stress, or a higher CTD, use more of the available water in the soil to avoid excessive dehydration (Blum, 1988; Ludlow and Muchow, 1990; Reynolds et al., 2007, 2009). Infrared thermometry can report subtle differences in leaf temperature in both field and controlled conditions (Blum et al., 1982; Jones et al., 2003, 2009; Chaerle et al., 2007; Winterhalter et al., 2011a,b). Importantly, data collection is fast and non-destructive.

CTD is useful mainly in hot and dry environments typical of countries with a Mediterranean climate. Measurements should preferably be made on recently irrigated crops on cloudless and windless days with high vapor pressure deficits. Under these conditions and provided that data are collected when the canopy is sufficiently expanded to cover the soil, CTD can be a good predictor of wheat GY $(r=0.6-0.8$; Reynolds and Pfeiffer, 2000). In bread wheat, yield progress was found to be associated with cooler canopies (Fischer et al., 1998) and significant genetic gains in yield have been reported in response to direct selection for CTD (Reynolds et al., 1999, 2009; Brennan et al., 2007). The addition of CTD as a selection criterion in wheat nursery improved considerably the identification of the highest yielding materials (van Ginkel and Ogbonnaya, 2007). These results are in keeping with the conclusions of Olivares-Villegas et al. (2007): “Canopy temperature epitomises a mechanism of dehydration avoidance expressed throughout the cycle and across latitudes, which can be utilized as a selection criterion to identify high-yielding wheat genotypes or as an important predictor of yield performance under drought."

Grant et al. (2006) investigated the robustness and sensitivity of thermal imaging for detecting changes in stomatal conductance and leaf water status in a range of plant species (grapevine, bean and lupin) under greenhouse or controlled environment conditions. In particular, they compared absolute leaf temperatures and thermal indices of plant stress with stomatal conductance and water potential. Thermal imaging successfully distinguished between irrigated and non-irrigated plants of different species, with strong correlations between thermal indices and stomatal conductance as measured with a leaf pyrometer. Their results also highlighted factors such as leaf angle that should be addressed when using thermal imaging for indirect measurement of the level of drought stress of the tested materials. Additionally, these results are valuable for the design of protocols for application in crop production or ecosystem monitoring.

\section{ABSCISIC ACID CONCENTRATION}

One of the main factors influencing leaf temperature via an effect on transpiration through stomatal conductance is the concentration of $\mathrm{ABA}$ in the leaf tissue and, ultimately, in guard cells (Wasilewska et al., 2008; Sirichandra et al., 2009). Therefore, ABA is a fundamental component of the mechanisms allowing the plant to match the water demand with the water supply and to optimize growth and survival in response to both daily and more long-term environmental fluctuations (Zhang and Davies, 1990; Xiong et al., 2007). Indeed, an increase in ABA concentration is a universal response observed in plants subjected to drought and other abiotic stresses (Quarrie, 1991; Setter, 2006). Additionally, ABA modulates the expression of a large number of genes whose products protect the cell from the harmful effects of dehydration (Bray, 2002; Seki et al., 2007).

ABA has been shown to affect many of the traits that influence the water balance of the plant through both dehydration avoidance and dehydration tolerance (Thompson et al., 2007). In maize seedlings subjected to artificially induced conditions of water deprivation, an increased $\mathrm{ABA}$ concentration enhanced the root/shoot ratio (Spollen et al., 2000; Sharp, 2002; Sharp et al., 2004), an adaptive change beneficial for increasing water uptake. It has also been shown that $\mathrm{ABA}$ facilitates water uptake into roots as the soil begins to dry, particularly under non-transpiring conditions, when the apoplastic path of water transport is largely excluded (Hose et al., 2001). Under terminal drought, tolerant pearl millet [Pennisetum glaucum (L.) R. Br.] have high leaf $\mathrm{ABA}$ and reduced transpiration at high vapor pressure deficit, a feature that highlights the important role of constitutive waterconserving mechanisms in maximizing yield under such conditions (Kholova et al., 2010a,b). The positive role on yield of a conservative water use, rather than deep or profuse rooting, has also been highlighted in chickpea (Zaman-Allah et al., 2011a,b).

In cereals, an accumulation of ABA has been implicated as one of the factors that influence reproductive fertility (Saini and Westgate, 2000; Landi et al., 2001b; Setter et al., 2001; Boyer and Westgate, 2004; McLaughlin and Boyer, 2007; Yang et al., 2007; Tang et al., 2008; Zhang et al., 2009) and endosperm development (Ober et al., 1991; Tuberosa et al., 1992; Setter et al., 1996; Mambelli and Setter, 1998; Seiler et al., 2011). In rice, selection for reduced ABA root signaling has been advocated as a means for better exploitation of subsoil water under mild or transient water deficit (Siopongco et al., 2008, 2009).

Sensitivity to ABA is also of interest for its implications on the adaptive response of plants to drought (Cominelli et al., 2005). Genetic variability for sensitivity to ABA has been reported in maize (Frascaroli and Tuberosa, 1993). Gametophytic selection carried out by spraying maize silks with an ABA solution before pollination led to significant effects on early vigor and other agronomic traits (Frascaroli and Landi, 1996; Landi et al., 2000).

Due to the availability of ABA-specific monoclonal antibodies (Quarrie et al., 1988) that allow for the cost-effective measurement of a large number of samples, several studies have been devoted to the identification of QTLs for ABA concentration and the analysis of their associated effects on other drought-related traits and yield (Lebreton et al., 1995; Tuberosa et al., 1998, 2002a; Sanguineti et al., 1999; Reymond et al., 2003; Giuliani et al., 2005; Landi et al., 2005, 2007; Rahman et al., 2011). Altogether, these studies do not provide a unifying picture of the role of $\mathrm{ABA}$ in determining yield, perhaps not unexpectedly in view of the different species and genetic backgrounds involved. Nevertheless, it is worth noting that the evaluation of an historical series of 
maize hybrids released in the past 60 years has shown a significant decrease in the capacity to accumulate ABA in response to a given level of water stress (Sanguineti et al., 2006) and, consequently, a negative correlation $(r=-0.62)$ between the capacity to accumulate ABA at the seedling stage (a trait never selected for by breeders) and GY.

\section{OSMOTIC ADJUSTMENT}

$\mathrm{OA}$ is a metabolic process entailing a net increase in intercellular solutes in response to water stress (Morgan, 1984; Zhang et al., 1999; Serraj and Sinclair, 2002). As soil moisture declines, OA favors turgor maintenance, and hence the integrity of metabolic functions. Importantly, OA can bias estimates of the value of relative water content, as has been shown in wheat and barley (Boyer et al., 2008).

OA has been implicated in sustaining yield under conditions of water deficit in oilseed Brassica species (Kumar and Singh, 1998), chickpea (Basu et al., 2007), cotton (Saranga et al., 2001), rice (Babu et al., 1999; Jongdee et al., 2002; Praba et al., 2009), sorghum (Tangpremsri et al., 1995), maize (Chimenti et al., 2006), tef (Ayele et al., 2001), barley (Gonzalez et al., 2008), and wheat (Ali et al., 1999; Blum et al., 1999; Salem et al., 2007; Ehdaie et al., 2008; Fan et al., 2008; Izanloo et al., 2008). Yet the value of $\mathrm{OA}$ as a desirable selection target from a breeding standpoint has been questioned (Munns, 1988; Palta et al., 2007), based on the notion that drought-tolerant genotypes endowed with a higher capacity to adjust osmotically are likely to be characterized by slow growth, and hence biomass production, due to the metabolic requirements of osmolyte biosynthesis. Under conditions of severe dehydration, a higher capacity to accumulate osmolytes may help plants withstand a prolonged drought spell and undergo a more prompt and complete recovery upon rehydration. Even though, the interpretation of osmotic relations in genetically engineered plants can be cumbersome (Blum et al., 1996), transformation experiments have shed light on the mechanisms by which plants may benefit from an altered capacity to accumulate osmolytes (Umezawa et al., 2006). Similarly to other drought-adaptive traits, the trade-off between the metabolic requirements of $\mathrm{OA}$ and the potential benefits for the crop varies on a case-by-case basis as a function of the crop, and the dynamics and severity of the drought episodes.

\section{CHLOROPHYLL CONCENTRATION, STAY-GREEN, AND DELAYED LEAF SENESCENCE}

A well-sustained source capacity is a key factor to maximize yield potential during both vegetative and reproductive phases, particularly under source-limiting conditions that commonly characterize drought-stressed crops. Therefore, delaying leaf senescence maintains transpiration and increases cumulative photosynthesis over the crop life cycle (Borrell et al., 2001; Jiang et al., 2004; Vadez et al., 2011). This is a strategy that is adequate for soils with appreciable water reserves but may otherwise cause severe stress at the end of the growth season due to increased transpiration.

The traits that have been monitored most frequently to obtain indirect estimates of photosynthetic potential are chlorophyll concentration, stay-green and delayed senescence, all of which are interconnected (Tuinstra et al., 1998; Thomas and Howarth,
2000; Shukla et al., 2004). In US Corn Belt maize, stay-green has improved significantly and steadily during the past six decades of breeding, particularly under favorable conditions (Duvick, 2005). Additionally, stay-green traits in maize correlate closely to GY, and multiple intervals of stay-green QTLs overlap with yield QTLs (Zheng et al., 2009). Although, stay-green in maize seems more likely to be related to nitrogen use, in sorghum it has been related to maintenance of a more favorable water status as related to root features (Gallais and Hirel, 2004; Blum, 2006; Mace et al., 2012). In sorghum, four major QTLs that control stay-green and GY have been identified (Harris et al., 2007) and near isogenic lines (NILs) for these QTLs have been derived, providing an opportunity for a detailed analysis of stay-green physiology and positional cloning of the underlying genes (Vadez et al., 2011).

\section{REMOBILIZATION OF WATER-SOLUBLE CARBOHYDRATES}

Remobilization of WSC from the stem and leaves can mitigate the negative effects on grain filling caused by post-anthesis drought tolerance (Blum, 1988, 1998; Araus et al., 2002; Reynolds et al., 2007; Rebetzke et al., 2008b). QTLs for stem-reserve remobilization have been reported in bread wheat (Salem et al., 2007; Snape et al., 2007; Yang et al., 2007). Rebetzke et al. (2008b) phenotyped three wheat mapping populations for WSC concentration (WSC-C) and for WSC mass per unit area (WSC-A). Genotypes with high WSC-C were commonly shorter, flowered earlier and produced significantly fewer tillers than those of low WSC-C. This resulted in similar yields, lower final biomass, and fewer grains per $\mathrm{m}^{2}$, but greater dry weight partitioning to grain and kernel weight in high versus low WSC-C genotypes. In contrast, lines high for WSC-A produced more fertile tillers associated with similar or greater anthesis and maturity biomass, grain number and yield, yet similar kernel weight or size compared with genotypes with low WSC-A, thus suggesting an important role for WSC-A in assuring stable yield and grain size in wheat.

This overview of drought-adaptive traits, far from being exhaustive, indicates that genetic variability in drought tolerance and WUE can be traced to the interaction of a multitude of quantitatively inherited morphophysiological features, whose effects on yield can vary greatly both in terms of magnitude and direction according to the prevailing drought scenario and other yield constraints. Therefore, the adoption of drought-adaptive traits as selection criteria for yield should be exercised cautiously and only after acquiring a clear understanding of the factors limiting yield in the TPE. Identifying the QTLs underpinning such traits and interpreting their cause-effect relationships allow us to partially disentangle this complexity to an extent and, eventually, make it amenable to a more direct and effective manipulation for breeding purposes. In both cases, good phenotypic data are essential to success.

\section{COLLECTING GOOD PHENOTYPIC DATA}

Plant scientists attempting to improve resistance to drought face two contrasting and apparently irreconcilable requirements. The first is to simplify "the system" in order to facilitate elucidation of the function of the relevant loci for the target traits (i.e., the reductionist approach). The second is to evaluate the broader value of such findings in a breeding and agronomically 
sound context (i.e., the holistic approach), where the physiology, epistatic interactions and pleiotropic effects of complex traits inevitably limit and blur the identification of the main factors leading to specific phenotypes (e.g., drought-resistant versus drought-susceptible). In a way, the reductionist approach is like trying to understand the subject of an entire puzzle when only a few pieces are available. On the other hand, the holistic approach selecting, for example, for yield per se will provide a complete picture of the puzzle (i.e., the phenotype). However, it will often not allow us to tease the puzzle apart to the extent that we would need to apply targeted approaches such as MAS and/or genetic engineering, because of our incomplete understanding of the number and function of the single pieces such are the QTLs for yield. Valuable opportunities to begin to reconcile this conundrum are provided by bioinformatics (Sawkins et al., 2004) and modeling (Hammer et al., 2004, 2006; Cooper et al., 2009; Tardieu and Tuberosa, 2010; Sinclair et al., 2010; Messina et al., 2011). Both modeling and high-throughput phenotyping for drought-adaptive features are at the very core of DROPS (DROught-tolerant yielding PlantS; www.drops-project.eu), an ongoing EU-funded project aiming at improving our understanding and capacity to ameliorate yield and yield stability under water-limited conditions.

Yet the objective of this review is not to dwell on the merits and pitfall of the reductionist and holistic approaches (see also Passioura, 2010). Rather, it seeks to introduce and discuss a number of major issues on phenotyping that are relevant for both approaches. These issues should be considered seriously in planning and managing experiments under drought conditions, collecting and analyzing the data and, eventually, in interpreting the results properly.

Given the myriad of factors that can influence the quality of phenotypic data, this review only addresses the most important ones. Although, it is possible to define general rules, each experiment has its own "phenotyping story" and the results should be dealt with and interpreted accordingly. What follows is equally relevant for the improvement of crop performance under waterlimited conditions and, more generally, for experiments in the field or under controlled conditions aimed at dissecting the physiological and genetic basis of crop adaptation to water-limited conditions. However, given the importance of field evaluation for breeding purposes, phenotyping under field conditions is emphasized.

\section{WHAT DOES “GOOD PHENOTYPING” MEAN?}

Good phenotyping is pivotal for reducing the genotypephenotype gap, especially for quantitative traits, which are the major determinants of drought resistance. Keeping a good record of meteorological parameters (rainfall, temperatures, wind, evapotranspiration, light intensity, etc.) allows for more meaningful interpretation of the results and identification of the environmental factors limiting yield (Sadras, 2002). Equally important, though often neglected or ignored, are the physical-chemical properties of the soil, particularly those influencing the water balance of the crop under decreasing moisture conditions (Cairns et al., 2011).
The basic attributes of good phenotyping carried out with appropriate genetic materials are accuracy and precision of measurements, coupled with relevant experimental conditions that are representative of the TPE. Accuracy involves the degree of closeness of a measured or calculated quantity to its actual (true) value. Accuracy is closely related to precision, also termed reproducibility or repeatability, the degree to which further measurements or calculations show the same or similar results. For a number of traits such as stomatal conductance, flow of xylem sap, etc., measured with mechanical or electronic devices, accuracy and precision in measurements require calibration of the instrument prior to data collection. Failure to so do will produce biased results with a difference between the mean of the measurements and the true reference value. A further complexity of phenotyping a large number of genotypes (e.g., a mapping population or an association mapping panel) for drought-adaptive features is exemplified by those traits such as stomatal conductance and tissue water potential, the value of which can vary considerably within a rather short timeframe due to changing environmental conditions.

An important distinction should be made between experiments aimed at (1) collecting data useful to dissect the genetic basis of target traits or (2) breeding activities for the release of improved cultivars. In both cases, an adequate choice of materials will be essential for successfully meeting the desired objectives. A notable case that clearly underscores the importance of good phenotyping is provided by QTL cloning (Salvi and Tuberosa, 2007). In this respect, the ideal scenario is when the alternative QTL alleles can be unequivocally scored phenotypically and the trait itself is mapped as one of the markers.

\section{PHENOTYPING IS KING AND HERITABILITY IS QUEEN}

Good phenotyping means not only the collection of accurate data to minimize the experimental "noise" introduced by uncontrolled environmental and experimental variability, but also the collection of data that are relevant and meaningful from a biological and agronomic standpoint, under the conditions prevailing in farmers' fields within the TPE. Although, hundreds of accurate studies reporting thousands of drought-responsive genes and QTLs can be found in the literature, the relevance of these data to "real" field conditions is often marginal and even questionable; only seldom has it been appropriately addressed and discussed. In the early stages following their development, evaluation of transgenic materials is limited to experiments carried out in greenhouses, a condition that underlines the importance to mimic as close as possible the drought stress conditions in fields (Saint Pierre et al., 2012).

Collecting accurate phenotypic data that are relevant to the TPE has always been a major challenge for the improvement of quantitative traits. The success of this endeavor is intimately connected with the heritability of the trait, namely the portion of the phenotypic variability accounted for by additive genetic effects that can be inherited through sexually propagated generations (Falconer, 1981). Trait heritability varies greatly (from 0 to 1) according to: (1) the genetic makeup of the materials under investigation; (2) the environmental conditions under which such materials are grown and evaluated; and (3) the 
accuracy and precision of the phenotypic data. With only a few notable exceptions (e.g., flowering time and carbon-isotope discrimination), most of the traits determining the performance of crops under drought conditions usually have low (0.3-0.4) or, at best, intermediate $(0.4-0.7)$ heritability. This impairs our capacity to dissect their genetic basis properly and, more importantly, reduces the effectiveness of phenotypic selection (Falconer, 1981). Despite this, careful evaluation and appropriate management of the experimental factors that lower the heritability of traits, coupled with a wise choice of the genetic material, can provide effective ways to increase heritability, and hence the response to phenotypic selection.

Once a sound association has been established between a marker and a locus affecting a target trait, the problems encountered in the conventional selection of quantitative traits, particularly the lowly-heritable ones, can been partially overcome through the use of markers linked to QTLs for the target trait. This enables individuals to be scored based on their genetic makeup rather than their phenotypic features (Peleman and Van der Voort, 2003; Langridge, 2005). Paradoxically, the probability of identifying the relevant chromosomal regions and accurately estimating their effects relies on good phenotyping of the genetic materials originally used to establish the phenotype-genotype associations. In other words, the effectiveness of marker-based approaches intimately depends on how well and how accurately the target trait has been assessed phenotypically in mapping populations. In fact, a low heritability impairs the probability of detecting the presence of QTLs (Bernardo, 2004), thereby increasing Type II errors (i.e., false negatives). An accurate and relevant phenotyping is of even greater importance when applying genome-wide selection, an approach that disregards QTL identification and relies on the molecular profiling and accurate phenotyping of each progeny (Bernardo and Yu, 2007; Bernardo, 2008; Heffner et al., 2009).

\section{EXPERIMENTAL DESIGN, DEDICATED SOFTWARE, AND STATISTICAL APPROACHES}

It is widely recognized that a substantial part of the increased efficiency of modern breeding is due to the accurate phenotyping of large numbers of plots, this scale-up being made possible by more sophisticated and high-throughput experimental machinery as well as the streamlining and automation of tedious manual operations. Thus, the labeling of a large number of plots and samples, data collection and storage, and keeping track of pedigrees, etc., are now facilitated by the use of electronics (e.g., bar-coding) and dedicated software (e.g., spreadsheets, databases, etc.). Additionally, the effectiveness of field experiments and the management and interpretation of phenotypic data can be enhanced greatly through the utilization of the most appropriate experimental designs to allow for better control of within-replicate variability and to reduce or remove spatial trends. Equally important are statistical approaches to analyzing the data, particularly for investigating the effects of GEI (van Eeuwijk et al., 2005; van Eeuwijk, 2006; Malosetti et al., 2008; Mathews et al., 2008; Messmer et al., 2009) and epistasis (Gao and Zhu, 2007; Jannink, 2007). Coping with the temporal variability of drought-adaptive features can be dealt with through in-depth analysis of QTL-by-environment interactions (van Eeuwijk et al., 2005; Vargas et al., 2006; Burgueno et al., 2008) or by identifying intrinsic characteristics of each genotype relating to its interaction with particular environmental conditions, which requires the development of models able to identify these variables and to simulate the behavior of genotypes in a broad range of environments (Tardieu, 2003; Yin et al., 2003; Reymond et al., 2004; Cooper et al., 2009; Sinclair et al., 2010).

A number of studies have shown the importance of epistasis in determining the genetic architecture of yield and other quantitative traits (Li et al., 2003b; Maccaferri et al., 2008; Zhao et al., 2008; Frascaroli et al., 2009; Messmer et al., 2009; Ravi et al., 2011). However, mapping two-way epistatic interactions requires adequately large mapping population, and detecting higher order epistasis is practically out of reach. Once different sets of NILs become available for loci that are known to interact epistatically, it will be possible to produce different combinations at will for further testing and characterization of the effects of such epistatic interactions.

\section{MONITORING PLANT-SOIL WATER RELATIONS}

A sound interpretation of the results of an experiment conducted under conditions of water shortage requires a good characterization of the soil-plant-atmosphere continuum (SPAC), which, in turn, relies on accurate monitoring of the water status of both soil and plant. From an experimental standpoint, an important issue is to what extent genotypic differences in drought-adaptive traits measured in phenotyping platforms at different water regimes reflect genotype performance across watering regimes under field conditions. Along this line, encouraging results have recently been reported in maize (Chapuis et al., 2012).

Regrettably, a unique means of measuring water status that can be applied in all possible situations is not available. Choosing the most appropriate method depends on the objective being pursued, such as understanding drought-adaptive mechanisms, selecting for drought resistance, investigating water movements, or managing irrigation treatments (Boyer, 1995; Kirkham, 2004; Jones, 2007). At the plant level, greater emphasis has traditionally been devoted to water potential rather than sustained turgor, the primary reason for sustained function under drought (Blum, 2006, 2009). Hence, examples of sustained function at low water status as the main reason for drought tolerance are comparatively few. Maintenance of high leaf water potential and turgor under dry conditions indicates dehydration avoidance (Blum, 1988; Ludlow and Muchow, 1990). Similarly, the relative water content of the leaf also provides important information on the water status of the plant, offering the advantage of collecting a high number of samples in a short time (Sanguineti et al., 1999), an important prerequisite for QTL studies trying to link variation in physiological parameters to variation in yield. The precautions to be adopted for measuring relative water content have been discussed by Blum ${ }^{2}$. Although, all components of leaf water relations change during the day as irradiance and temperatures vary, the change is small for about $2 \mathrm{~h}$ at and after solar noon. Therefore,

\footnotetext{
${ }^{2} \mathrm{http} / /$ www.plantstress.com/methods/index.asp
} 
this is an appropriate time window for investigating leaf water relations in a large number of genotypes ${ }^{2}$.

It is equally important to monitor changes in soil moisture, preferably at different depth of the rhizosphere, during the growth and reproductive cycle of the crop. Root water uptake is one of the pivotal processes within the SPAC. While the gravimetric method (i.e., weighing samples of soil columns before and after oven drying) provides accurate, albeit time-consuming, measurement of soil moisture, other methods such as the neutron probe, the capacity method and the "I-sensor" allow for quicker and less labor-intensive measurement (Nagy et al., 2008; Cayci et al., 2009).

During recent decades, progress in microelectronics has allowed the development of several dielectric-based soil water monitoring techniques, namely time-domain reflectometry (TDR), and single and multisensor capacitance probe (SCP/MCP) systems (Fares and Polyakov, 2006; Vereecken et al., 2008). These techniques have greatly simplified the real-time determination of water content on a fine spatial and temporal scale. Because of their relatively low cost and ease of operation, MCP systems have met widespread acceptance as a means of closely monitoring soil moisture by collecting high-resolution soil-water content data in the rhizosphere. Despite their success, MCP systems have shown some temperature and salinity effects in different soil types, suggesting that further research is needed to eliminate such effects for these capacitance systems to take their place as leading soil water monitoring sensors.

TDR has been one of the most widely used techniques to determine soil volumetric water content thanks to its high precision, non-ionizing radiation and low influence of soil salinity, bulk density and texture (Noborio, 2001). However, compared to the neutron probe, most of the TDR equipment available does not allow detailed measurement along the soil profile. Also, the use of conventional TDR probes requires drilling holes or opening trenches in the soil to install the probes, limiting the number of points measured in the soil profile (Manieri et al., 2007). More recently, two-dimensional geoelectrical tomography has been used for monitoring soil-water redistribution due to water uptake by lupin roots (Werban et al., 2008). The resulting average water content from two-dimensional geoelectrical tomography agreed well with the values determined by the TDR measurements model.

\section{WHAT SEVERITY OF WATER SHORTAGE?}

Unlike yield under conditions of severe drought stress (>70\% reduction from yield under well-watered conditions) yield under more moderate water shortage (up to approximately $50 \%$ reduction) reflects more closely yield potential under favorable conditions (Blum, 2006). Therefore, drought resistance per se is expected to play a progressively more important role than yield potential as the severity of drought escalates, with genotype ranking for yield changing considerably once the mean yield falls below 20-30\% of yield potential (Blum, 2006) as a result of water scarcity. Consequently, germplasm evaluation in areas where drought severity fluctuates widely should preferably be carried out under well-watered conditions and at different levels of drought stress (e.g., intermediate and severe). In maize, this approach has been adopted to identify QTLs for yield across a broad range of water availability (Malosetti et al., 2008; Messmer et al., 2009) and to develop superior hybrids in sub-Saharan Africa (Bänziger et al., 2006).

Retrospective studies conducted with an historical series of maize hybrids showed that screening in multiple sites at high plant densities provides substantial yield gains across a broad range of environments, although, rates of gain in well-watered conditions are more than twice as high as those in water-stressed environments (Duvick, 2005; Campos et al., 2006). In wheat, four decades of breeding at CIMMYT have clearly indicated the importance of selecting and managing key environments differing in their yield potential to identify the best performing genotypes across a broad range of environments. The so-called "shuttle breeding" which was instrumental for the success of the Green Revolution (Borlaug and Dowswell, 2005), remains a key factor in developing more broadly adapted cultivars (Ortiz et al., 2007b; Trethowan and Crossa, 2007). Recently, a QTL with a major and consistent effect on GY in multiple elite genetic backgrounds under both water-stressed and non-stressed conditions has been described (Vikram et al., 2011). Consistency of the QTL effect across different genetic backgrounds makes it a suitable candidate for use in marker-assisted breeding.

\section{PHENOTYPING IN THE FIELD}

Assuming that both the type and the number of treatments (genotypes, irrigation volumes, etc.) to be evaluated are adequate for the specific objectives of each experiment, the following general factors should be evaluated carefully to ensure the collection of meaningful phenotypic data in field experiments conducted under water-limited conditions:

- Experimental design

- Heterogeneity of experimental conditions between and within experimental units

- Size of the experimental unit and number of replicates

- Number of sampled plants within each experimental unit

- Genotype-by-environment-by-management interaction.

The relative impact of each factor on the quality of the phenotypic data to be collected will vary greatly according to each experiment. As an example, an excessive heterogeneity in soil characteristics (depth, moisture, $\mathrm{pH}$, etc.), and/or compaction among field plots will inevitably increase the experimental error and will jeopardize an accurate evaluation of yield. Mapping the soil in experimental nurseries for environmental factors that decrease phenotypic accuracy (Cairns et al., 2004, 2011; Rossel et al., 2006; Patzold et al., 2008) and adopting suitable experimental designs can partially mitigate the negative effects of high soil heterogeneity.

For experimental activities carried out under drought conditions, the additional factors discussed below should receive due attention when planning and conducting the experiments.

\section{VARIATION IN PHENOLOGY}

In environments where escape is the predominant cause of drought resistance, the presence of large differences in flowering 
time among genotypes will inevitably bias the interpretation of the influence of drought-adaptive traits on yield under drought conditions (Soltani and Sinclair, 2012). Likewise, the presence of large differences in plant height and/or root mass among the progeny of a mapping population or accessions of a panel suitable for association mapping studies, may lead to an overestimate of QTL effects owing to competition between neighboring plots, especially when their surface area is small. These QTL effects will most likely decrease once phenotypic evaluation has been carried out with more phenologically homogeneous materials. Surprisingly, this issue has not yet been addressed with dedicated experiments.

\section{INTERACTIONS WITH OTHER STRESSES}

Obtaining an accurate estimate of drought resistance per se implies the absence of other biotic or abiotic stress agents that influence plant growth and function. Typical case scenarios are those involving factors that cause mechanical damage to roots (e.g., nematodes, root-worms, etc.), impair root growth (e.g., soil acidity, boron toxicity, salinity, etc.), and/or reduce water availability to the crop (e.g., presence of weeds), and source capacity (e.g., foliar diseases, insect damage to the canopy, etc.). When one or more of the above-mentioned constraints affects the experimental plots, genetic variability among the progeny in resistance to these stress agents will inevitably bias an accurate evaluation of drought resistance. Likewise, important and more subtle interactions may occur when the effects of water deficit are evaluated in the presence of other abiotic stress factors (e.g., high temperatures, high ozone, low nutrients, etc.) that hasten leaf senescence and/or enhance the role of specific adaptive mechanisms, such as the relocation of stem WSC in cereals, that normally play a less predominant role in determining yield.

Nevertheless, it should be noted that drought hardly ever occurs in the absence of other stress factors (Sadras, 2002; Sinclair et al., 2007). An example of this is provided by the conditions of terminal drought stress frequently concomitant to high temperatures that wheat and rice experience during grain filling (Pinto et al., 2010; Jagadish et al., 2011; Lopes et al., 2012; Yang et al., 2012). A partial solution to this problem, at least for traits other than GY and its components, which are best evaluated under field testing, is to collect phenotypic data from plants grown in controlled facilities (greenhouse, growth chamber etc.). This will allow for an accurate control of the main environmental parameters-temperature, air humidity, light, etc.,-governing water flow in the SPAC, and hence the water balance. This is particularly important for omics-profiling studies where even small fluctuations in environmental conditions can substantially alter gene expression. On a broader scale, environmental characterization can be improved through the use of geographic information systems (GIS) for crop monitoring (Kahinda et al., 2008), for water balance models (Reshmidevi et al., 2008) and for their combination.

\section{MANAGING THE DYNAMICS AND INTENSITY OF DROUGHT EPISODES}

The ability to control the timing, frequency and intensity of drought episodes is a key factor in mimicking the environmental conditions prevailing in the TPE and, consequently, in successfully selecting for improved drought resistance. To this end, an increasing number of public and private breeding programmes have conducted field trials in locations characterized by very low rainfall during the growing season, a condition under which the dynamics and intensity of drought episodes can be tightly controlled through the frequency and volume of irrigation treatments. Trials in dry sites also offer the distinct advantage of a lower incidence of biotic constraints which, if unaccounted for, can bias the evaluation of the role of other traits and corresponding QTLs in the adaptive response to moisture-limited conditions.

The option of field testing in dry areas is not always available to many of those engaged in drought-related experiments. Therefore, rainout shelters offer the possibility of investigating the adaptive response of crops to a desired level of drought stress, avoiding the vagaries of unpredictable rainfall patterns. There are basically two types of rainout shelter: static and moveable. Further details on the merits and pitfalls of these devices are provided by Blum². Major drawbacks to the use of rainout shelters are high construction and operating costs, particularly for the movable type, as well as the usually rather limited area protected by a shelter which, in turn, limits the number and size of experimental plots that can be tested. This is a significant problem when dealing with large mapping populations or panels of accessions suitable for association mapping studies.

\section{INFLUENCE OF THE GROWTH STAGE}

An important aspect for phenotyping traits in the most relevant way from a breeding point of view is the identification of the critical stage at which variability in the target traits plays a more prevalent role in final performance. This is the stage at which the correlation between the trait and final yield is highest, and thus becomes more diagnostic. For example, in maize some biochemical factors, such as the concentration of sucrose in the placental-chalazal area of the kernel, exert a particularly strong and timely effect on reproductive fertility around flowering but not a week earlier or later (Boyer and Westgate, 2004; McLaughlin and Boyer, 2004). Similarly, genetically-based differences in the concentration of ABA in leaves of field-grown maize have been shown to peak around the time of flowering or shortly after (Landi et al., 1995; Pekic et al., 1995). Due consideration should also be given to fluctuations in the heritability of target traits exhibited during the growth cycle (see below).

A critical factor in improving the relevance of infrared thermography to measure canopy temperature is the timing of the measurements of temperature differences between treatments. Under field conditions, even well-watered healthy plants may shut their stomata before solar noon, especially under conditions of high evapotranspirative demand. This is particularly relevant when different genotypes are evaluated for their capacity to exploit an avoidance strategy. In this case, the timing of the measurements to allow good discrimination among genotypes needs to be determined for specific conditions and may need considerable readjustment during subsequent samplings as the water stress progresses during the day. An additional factor 
to be considered when measuring canopy temperature is the effect of leaf wilting, folding or rolling under stress (Leinonen et al., 2006; Grant et al., 2007). For instance, plant canopy architecture will influence leaf temperature not only through the angle of leaves to the light source, but also through the degree of self-shading in the canopy (Zheng et al., 2008). To a certain extent, the influence of self-shading can be reduced if the most suitable view angle is used, although, different opinions have been expressed in this regard (Grant et al., 2006).

When phenotyping occurs at flowering or shortly after, additional bias is introduced if the tested genotypes differ considerably in flowering time and/or maturity. In such cases, phenotyping all accessions on the same date will provide data collected from plants at different physiological stages, a circumstance that could introduce significant bias in the interpretation of cause-effect relationships between traits and yield. A partial solution is to sow the accessions on two or three dates based on the maturity group (e.g., early and late). Clearly, this procedure will increase the cost of the trial.

\section{TIMING OF MEASUREMENT AND SAMPLE COLLECTION}

For morphophysiological traits that fluctuate widely during the circadian cycle (e.g., water status, ABA content, stomatal conductance, leaf rolling, leaf temperature, etc.) choosing the most appropriate time for measurement and/or sample collection is very critical. Additionally, measurement of traits that are timeconsuming to record (e.g., stomatal conductance) in a large number of plants introduces a covariate effect proportional to the duration of data or sample collection. In this respect, remote sensing holds great potential to minimize or eliminate altogether effects on trait expression due to the circadian rhythm and corresponding changes in environmental factors.

CTD is a notable indicator of the amount of water extracted from the soil and lost through foliar evapotranspiration into the atmosphere. Therefore, this trait provides an indirect estimate of root architecture (size and depth) and functionality (e.g., permeability to water as a function of aquaporines, etc.) in accessing soil moisture, and can be used as a fast, inexpensive screening of root features (Reynolds et al., 2009). However, to be diagnostic, canopy temperature should be measured under conditions of high evapotranspirative demand and in absence of wind (Blum, 1988), since even a slight breeze can alter the level of evapotranspiration instantaneously and, consequently, alter the leaf temperature. Balota et al. (2007) have investigated the effects of the timing of measuring CTD on breeding selections of wheat in relation to growth stage, time of day and weather. Although, under dry conditions long-term mean CTD at noon and yield were found to be correlated in two growing seasons, the relation of short-term CTD readings to GY was highly variable (Balota et al., 2007). Poor correlation was associated with days of low solar irradiance, high wind speed and rain events. Interestingly, genotype effects on CTD were detected for all hours of day and night. Genotype-by-hour interaction was non-significant at night, suggesting that night-time measurements may provide more stable conditions for CTD comparison among genotypes.

\section{PHENOTYPING IN CONTROLLED ENVIRONMENT FACILITIES}

Although, GY and its components are best phenotyped in field trials, measuring secondary traits in plants grown in controlled environment facilities (e.g., greenhouse, growth chamber, etc.) takes advantage of an accurate control of the main environmental parameters of moisture stress, air humidity, temperature, light, etc., that vary greatly in field experiments. However, the conditions under which plants are grown should be relevant to the conditions prevailing in the field (Izanloo et al., 2008). When the materials under test differ in flowering time, the use of plants grown under controlled conditions facilitates the collection of phenotypic data and samples at the same growth stage and under similar conditions. Additionally, a tight control of growing conditions allows for more accurate assessment of the constitutive capacity of different genotypes to accumulate drought-adaptive compounds in response to a given level of water deficit. For example, the accumulation of osmolytes and/or ABA is highly influenced by water status, which can vary considerably among genotypes tested in the field under similar water regimes (Tuberosa et al., 1994; Rauf et al., 2009).

More uniform conditions in terms of water status can be achieved through exposing plants to a solution with a known concentration of polyethylene-glycol (PEG). This approach can be of particular interest as a way of exposing different genotypes to a given level of dehydration (Sanguineti et al., 2006; Verslues et al., 2006; Texeira et al., 2008; Ruta et al., 2010). Unlike in field conditions where different genotypes are likely to experience different stress intensities, plants grown in a PEG solution are exposed to predetermined and rather uniform water stress, a condition that facilitates a more correct interpretation of the cause-effect relationships of the association between traits. However, the use of PEG requires good aeration of the solution to avoid hypoxia and verification of the absence of possible contaminants. Additionally, plants absorb PEG, particularly when it is of a low molecular weight $(<6000)$, which can alter the hydraulic properties of the leaf ${ }^{2}$. Therefore, great caution should be adopted in taking results obtained under such highly artificial conditions and extrapolating them to field conditions.

In most circumstances, the collection of phenotypic data in experimental conditions that are remote from those prevailing in the field may lead to biased and potentially misleading conclusions. At the molecular level, an interesting example is provided by transcriptomics studies (Atienza et al., 2004; Rensink, 2005) wherein plants or plant parts such as detached leaves undergo high-intensity stress treatments in a rather short time, i.e., "shock-like" treatments. These conditions preclude the identification of long-term responses in gene expression that play a more predominant role in adaptation to field aridity (Passioura, 2010). In barley, changes in gene expression were monitored in leaves of plants grown in soil and subjected to slow-drying conditions for 7 and 11 days (7d-WS and 11d-WS, respectively) with the changes obtained under "shock-like" conditions imposed with a $6 \mathrm{~h}$ dehydration treatment (Talamè et al., 2007). Among all transcripts that showed a significant change in regulation in at least one of the conditions tested, $57 \%$ were exclusively affected in the dehydration shock treatment, $6 \%$ at $7 \mathrm{~d}-\mathrm{WS}$ and $14 \%$ at $11 \mathrm{~d}-$ WS. Irrespective of the low percentage of transcripts (10\%) with 
similar expression changes between shock- and slow-stress treatments, a portion of these transcripts shared a common expression trend under the different drought treatment conditions, as evidenced by low correlations between the fast-occurring and the $7 \mathrm{~d}$-WS and $11 \mathrm{~d}$-WS treatments $(r=0.32$ and 0.41 , respectively). From a practical standpoint, these results suggest that the information obtained under artificial conditions of water deficit induced over a very short period of time (e.g., a few hours) should be treated very cautiously when used to identify candidate genes for QTLs of field-related traits with a drought-adaptive role.

\section{HARNESSING PHENOTYPIC VARIABILITY}

A number of options are available to utilize the information collected through phenotypic evaluation of germplasm resources (Gur and Zamir, 2004; Dreccer et al., 2007; Reynolds et al., 2007; Richards et al., 2007; Ortiz et al., 2008; Bernardo, 2009; Di Bianco et al., 2011; Tuberosa et al., 2011a). A well-informed choice of the parental lines based on a thorough phenotypic characterization of the main traits imparting drought resistance allows for the creation of new populations where segregants that combine drought-adaptive and other desirable features of parental lines can be identified and selected (Reynolds et al., 2005). This so-called "strategic crossing" has been deployed extensively and successfully at CIMMYT, as shown by the fact that several newly released improved wheat accessions have been selected from crosses between parental lines chosen based on their morphophysiological features (Reynolds et al., 2005, 2011; Ortiz et al., 2007b).

An effective breeding programme relies on the availability of sufficient genetic variability for the target traits. Under this aspect, landraces and wild accessions provide valuable opportunities to enhance the variability for drought-adaptive features and, eventually, yield (Moncada et al., 2001; Talamè et al., 2004; Tan et al., 2008). There is rapidly growing interest in wild relatives of crops and landraces as sources of agronomically superior alleles among those that were left behind by the domestication bottleneck and modern agriculture (Tanksley and McCouch, 1997; Lippman et al., 2007; Reynolds et al., 2007; Feuillet et al., 2008). Advanced-backcross QTL analysis (ABQA) and introgression libraries (ILs) allow for proper and effective dissection of the phenotypic variability contributed by non-commercially viable parental lines (Talamè et al., 2004; Tan et al., 2008; Salvi et al., 2011). Once a desirable QTL feature contributed by unadapted materials tested under drought conditions has been identified, the main issue is to evaluate to what extent the introgression of the target segment in elite materials might cause a yield penalty under favorable conditions. Regarding target traits, landraces and wild relatives have been screened most commonly to identify accessions with an outstanding expression of secondary traits such as root mass, OA, leaf anatomy, etc., thought to play an important role in conferring resistance to drought (Grando and Ceccarelli, 1995; Peleg et al., 2007, 2008).

\section{TOWARD HIGH-THROUGHPUT PHENOMICS}

High-throughput phenotyping helps standardize and improve the collection of phenotypic data and facilitates the creation of repository databases useful for QTL meta-analyses (Lippman et al., 2007; Welcker et al., 2011). Unlike a decade ago, our present capacity to conduct high-throughput molecular profiling far outweighs our capacity to collect reliable phenotypic data (Sinclair and Purcell, 2005). The best example is provided by the burst in single nucleotide polymorphism (SNP) discovery and profiling in a number of crops (Rostoks et al., 2005; Kota et al., 2008; Ganal et al., 2009; Waugh et al., 2009; Mondini et al., 2011; Rafalski, 2011; Trebbi et al., 2011). Nevertheless, the past years have witnessed a growing awareness of the need for increasingly integrated, multidisciplinary and field-oriented research in order to mitigate the negative effects of water shortage (Edmeades et al., 2004; Tuberosa et al., 2007a).

High-throughput phenotyping of plants in pots allows for tight control of the water shortage imposed on different genotypes and of the homogeneity of the severity of stress, a condition that is seldom achieved under field conditions, particularly when the genotypes under test differ in phenology and/or biomass. However, a number of distinct limitations characterize pot experiments and should be carefully considered and managed to obtain meaningful results relevant to field conditions (Passioura, 2006).

Phenotyping under controlled conditions is relatively straightforward when scoring traits in a binary fashion, such as for photoperiod sensitivity, and when environmental conditions do not have much effect on the target trait or are easily defined (e.g., light versus darkness). However, it quickly becomes more complex when the target traits are quantitatively assessed, as in the case of growth, and when environmental conditions that vary during the day (e.g., temperature, light intensity, soil water status, etc.) influence the target trait (e.g., the rate of leaf elongation). In this case, the phenotype is rather dynamic and better defined by a series of response curves to environmental stimuli (Tardieu et al., 2003, 2005; Hammer et al., 2004; Tardieu, 2012), an approach that is very time-consuming and requires a tight control of environmental conditions.

Hence, it is important to: (1) measure the physical variable/s (e.g., pot weight, soil moisture etc.) that quantify the level of water stress; and (2) add a precise amount of water to each pot. Highthroughput phenotyping platforms allow for the automation of these procedures that have already been adopted by a number of private companies and large public institutions to streamline and standardize the collection of highly accurate phenotypic data in glasshouse-grown plants (Granier et al., 2006; Rajendran et al., 2009). State-of-the art technology including imaging, robotic and computing equipment, allows for the continuous phenotypic measurement of thousands of plants automatically and nondestructively ${ }^{3}$. Regrettably, the installation and operating cost of these platforms is very high.

For certain traits, the high-throughput collection of phenotypic features can be streamlined by the use of digital imaging and measurement of canopy features by means of near-infrared spectroscopy and spectral reflectance, as discussed below.

\section{DIGITAL IMAGING}

Digital image analysis provides an inexpensive and rapid way of precisely measuring plant features whose measurement would

\footnotetext{
${ }^{3}$ See the "Plant Accelerator" at http://www.plantphenomics.org/TPA
} 
otherwise require a great deal of time. A notable example is provided by the measurement of canopy features (Marti et al., 2007; Campillo et al., 2008; Elsayed et al., 2011; Winterhalter et al., 2011b; Fiorani et al., 2012). Digital images offer a series of advantages over other methods of light interception estimation, including the possibility of directly processing images by computer. Video image analysis allows for a dynamic, inexpensive and non-destructive assessment of canopy features and crop growth (Beverly, 1996; Campillo et al., 2008; Cairns et al., 2011; Elsayed et al., 2011; White et al., 2012). Digital imaging is equally valuable for measuring root characteristics in experiments that are often constrained by the lack of suitable methods for continuous, non-destructive measurements (Himmelbauer et al., 2004; Blouin et al., 2007). Additionally, digital image analysis (Kimura et al., 1999; Armengaud et al., 2009) allows for accurate analysis at higher resolution scales, an important prerequisite to investigate the kinetics of the processes regulating root growth. In this respect, a non-invasive technique, based on digital image sequence processing, has been applied for quantifying highly resolved spatio-temporal processes within the root growth zone in the model plant Arabidopsis (Chavarria-Krauser et al., 2008; Iyer-Pascuzzi et al., 2010).

\section{NEAR-INFRARED SPECTROSCOPY AND SPECTRAL REFLECTANCE}

Remote sensing via near-infrared spectroscopy and spectral reflectance of plant canopies are promising components of highthroughput phenotyping platforms (Montes et al., 2007) and provide interesting opportunities for collecting integrative traits with high temporal resolution (Gutierrez et al., 2010). Spectral reflectance in the visible and near-infrared regions of the electromagnetic spectrum is collected from the canopy of the crop by sensors that can be mounted on tractors (Montes et al., 2007) or using digital cameras mounted on hand-held devices (Casadesus et al., 2007). Remote sensing has advanced our understanding of the changes in leaf reflectance and leaf emittance according to species, leaf thickness, canopy shape, leaf age, nutrient status and, importantly, water status (Hatfield et al., 2008). Based on this information, various vegetative indices for crop canopies have been formulated to quantify agronomic parameters (e.g., leaf area, crop cover, biomass, yield, etc.). Retrieving meaningful information from the plot spectra relies on the use of calibration models for prediction of the phenotypic values. Under well-managed experimental conditions, spectral reflectance has been used to monitor plant photosynthetic pigment composition, water status assessment and the early detection of abiotic stress (Babar et al., 2006, 2007; Guo et al., 2008; Gray et al., 2010).

\section{SIMULATING VIRTUAL PHENOTYPES}

As we inch our way forward to unravel gene functions in a piecemeal fashion (i.e., gene-by-gene) and try to understand how these functions ultimately affect the phenotype, there is a growing interest in models that allow us to simulate virtual phenotypes deriving from all possible combinations of different factorsalleles, environmental variables, etc. In a way, modeling represents a step toward a more comprehensive systems biology approach (Dingkuhn et al., 2005; Yin and Struik, 2008; Tardieu and Tuberosa, 2010) aimed at predicting phenotypic performance of an otherwise intractably large number of treatments, such as the genotypes obtained by combining different gene/QTL alleles, irrigation volumes and frequency, temperatures, etc., (Hoogenboom et al., 2004; Cooper et al., 2007; Heinemann et al., 2008; Letort et al., 2008; Sinclair et al., 2010).

The assumption is that gene networks are regulated in a coordinated way to allow plants to react predictably to a range of environmental conditions (Sadok et al., 2007; Chenu et al., 2008; Jansen et al., 2009; Chapuis et al., 2012). Crucial to the success of this approach is the possibility of monitoring the phenotype of each accession in a precise and rapid way for the target trait (e.g., leaf elongation) in response to closely controlled environmental variables such as temperature, evaporative demand, soil water status, etc. Clearly, this kind of study is best conducted under controlled conditions. In maize, the QTL parameters of these responses were calculated for lines of mapping populations and were then analyzed genetically (Reymond et al., 2003; Welcker et al., 2007), allowing simulation of leaf growth in novel inbred lines as defined by their QTL alleles (Sadok et al., 2007). Therefore, this approach allows for the identification of QTLs of plant responses that, in principle, should not include a GEI. It theoretically allows prediction of the performance of any "virtual genotype" with a given combination of alleles in any climatic scenario. This possibility opens up a promising avenue, but is limited at present to very simple traits and genetic systems.

More integrative models simulate crop development as a function of environmental conditions. Consequently, they allow for the evaluation of the effects of individual traits on the seasonal dynamic of water use and carbon assimilation of crops (Chapman et al., 2003; Yin et al., 2004). However, their algorithms remain relatively crude, so the effects of genes or QTLs cannot usually be simulated at the crop level except for constitutive traits such as phenology (Chapman et al., 2003; Yin et al., 2005), for binary traits related to environmental triggers, such as flowering response to photoperiod (Hoogenboom et al., 2004) or when QTL models at the organ level can be combined with crop models (Chenu et al., 2008; Tardieu and Tuberosa, 2010). Their main function until now has been to evaluate whether a given trait will have a positive effect over a long series of climatic scenarios. For instance, Hammer et al. (2005) simulated the effect of staygreen, a trait considered as conferring drought tolerance, across 547 location-season combinations. As expected, this trait had a positive effect under mid-season or terminal stress, but a negative effect under severe terminal stress.

A factor that affects the prediction capacity of modeling is the unaccounted complications caused by non-linear effects associated with genes acting in networks when selection is conducted on a population of individuals segregating for the genes contributing to the network (Peccoud et al., 2004). Notwithstanding the promising features of modeling, an accurate prediction across genotypes still remains a difficult undertaking.

\section{CONCLUSIVE REMARKS AND PERSPECTIVES}

Taking full advantage of germplasm resources and the opportunities offered by genomics approaches to improve drought resistance will require a better understanding of the physiology and genetic basis of drought-adaptive traits. Clearly, an accurate and 
cost-effective phenotyping will be instrumental in this respect. The utilization of techniques/approaches that allow for a precise control of the water regime (e.g., irrigated trials in dry regions, rainout shelters, etc.) and a reduction of the experimental noise coupled with the adoption of high-throughput platforms will streamline the collection of good phenotypic data while increasing the cost-effectiveness of phenotyping. This, in turn, will help to lift, at least partially, the "statistical fog" that surrounds QTLs and impairs our capacity to properly gauge their effects and predict the potential of novel combinations of QTL alleles.

However, no matter how accurate our phenotyping will be, the vast majority of the QTLs determining the measured phenotype will remain undetected. By analogy, I refer to this as the "iceberg effect." Similar to an iceberg, where most of mass lies below the sea surface and thus is not visible, the majority of the genetic factors controlling quantitative traits will equally defy detection because their effects are simply too small to be evidenced at a statistically significant level. Therefore, notwithstanding the implementation of new crossing schemes (e.g., multiparental crosses: Blanc et al., 2006, 2008) and approaches (e.g., association mapping: Buckler

\section{REFERENCES}

Acuna, T. L. B., Lafitte, H. R., and Wade, L. J. (2008). Genotype $\times$ environment interactions for grain yield of upland rice backcross lines in diverse hydrological environments. Field Crops Res. 108, 117-125.

Acuna, T. L. B., Pasuquin, E., and Wade, L. J. (2007). Genotypic differences in root penetration ability of wheat through thin wax layers in contrasting water regimes and in the field. Plant Soil 301, 135-149.

Alhosein, I., Miyuki, N., Shuhei, N., Kenji, K., Masaya, F., Hitoshi, M., and Yutaka, O. (2012). Novel QTLs for growth angle of seminal roots in wheat (Triticum aestivum L.). Plant Soil 354, 395-405.

Ali, M., Jensen, C. R., Mogensen, V. O., Andersen, M. N., and Henson, I. E. (1999). Root signaling and osmotic adjustment during intermittent soil drying sustain grain yield of field grown wheat. Field Crops Res. 62, 35-52.

Ali, M. L., Pathan, M. S., Zhang, J., Bai, G., Sarkarung, S., and Nguyen, H. T. (2000). Mapping QTLs for root traits in a recombinant inbred population from two indica ecotypes in rice. Theor. Appl. Genet. 101, 756-766.

Araus, J. L., Amaro, T., Zuhair, Y., and Nachit, M. M. (1997). Effect of leaf structure and water status on carbon isotope discrimination in field-grown durum wheat. Plant Cell Environ. 20, 1484-1494.

Araus, J. L., Blum, A., Nguyen, H. T., Parry, M. A. J., and Tuberosa, R. (2007). Integrated approaches to sustain and improve plant production under drought stress-preface. J. Exp. Bot. 58, iv.

Araus, J. L., Bort, J., Steduto, P., Villegas, D., and Royo, C. (2003). Breeding cereals for Mediterranean conditions: ecophysiological clues for biotechnology application. Ann. Appl. Biol. 142, 129-141.

Araus, J. L., Slafer, G. A., Reynolds, M. P., and Royo, C. (2002). Plant breeding and drought in $\mathrm{C} 3$ cereals: what should we breed for? Ann. Bot. 89, 925-940.

Araus, J. L., Slafer, G. A., Royo, C., and Serret, M. D. (2008). Breeding for yield potential and stress adaptation in cereals. Crit. Rev. Plant Sci. 27, 377-412.

Arihara, J., and Crosbie, T. M. (1982). Relationships among seedling and mature root system traits of maize. Crop Sci. 22, 1197-1202.

Armengaud, P., Zambaux, K., Hills, A., Sulpice, R., Pattison, R. J., Blatt, M. R., and Amtmann, A. (2009). EZRhizo: integrated software for the fast and accurate measurement of root system architecture. Plant J. 57, 945-956.

Ashraf, M. (2010). Inducing drought tolerance in plants: recent advances. Biotechnol. Adv. 28, 169-183.

Asseng, S., Turner, N. C., Botwright, Y., and Condon, A. G. (2003). Evaluating the impact of a trait for increased specific leaf area on wheat yields using a crop simulation model. Agron. J. 95, 10-19.

Atienza, S. G., Faccioli, P., Perrotta, G., Dalfino, G., Zschiesche, W., Humbeck, K., Stanca, A. M., and Cattivelli, L. (2004). Large scale analysis of transcripts abundance in

et al., 2009; Lu et al., 2010, 2012; Maccaferri et al., 2011; Varshney et al., 2012) that facilitate the identification and cloning of QTLs, the targeted manipulation of yield will remain a daunting undertaking.

As compared to MAS, genome-wide selection, while bypassing QTL identification (Bernardo, 2009), relies even more so on accurate phenotyping. As the cost of genotyping and sequencing keeps dropping (Varshney et al., 2009; Feuillet et al., 2011), cost-effective phenotyping will become increasingly strategic for further dissecting drought-adaptive traits and tailoring cultivars better suited for farming under drought-prone conditions. Hopefully, the information presented in this review will help raising interest in phenotyping as well as due awareness and appreciation of its pivotal role.

\section{ACKNOWLEDGMENTS}

This review was written in the framework of the DROPS project, which received funding from the European Community's Seventh Framework Programme under the grant agreement $n^{\circ}$ FP7-244374.

barley subjected to several single and combined abiotic stress conditions. Plant Sci. 167, 1359-1365.

Ayele, M., Blum, A., and Nguyen, H. T. (2001). Diversity for osmotic adjustment and root depth in tef [Eragrostis tef (Zucc) Trotter]. Euphytica 121, 237-249.

Azhiri-Sigari, T., Yamauchi, A. Kamoshita, A., and Wade, L. J. (2000). Genotypic variation in response of rainfed lowland rice to drought and rewatering. II. Root growth. Plant Prod. Sci. 3, 180-188.

Babar, M. A., van Ginkel, M., Klatt, A., Prasad, B., and Reynolds, M. P. (2006). The potential of using spectral reflectance indices to estimate yield in wheat grown under reduced irrigation. Euphytica 150, 155-172.

Babar, M. A., van Ginkel, M., Reynolds, M. P., Prasad, B., and Klatt, A. R. (2007). Heritability, correlated response, and indirect selection involving spectral reflectance indices and grain yield in wheat. Aust. J. Agric. Res. 58, 432-442.

Babu, R. C., Nguyen, B. D., Chamarerk, V., Shanmugasundaram, P., Chezhian, P., Jeyaprakash, P., Ganesh, S. K., Palchamy, A., Sadasivam, S., Sarkarung, S., Wade, L. J., and Nguyen, H. T. (2003). Genetic analysis of drought resistance in rice by molecular markers: association between secondary traits and field performance. Crop Sci. 43, 1457-1469.

Babu, R. C., Pathan, M. S., Blum, A., and Nguyen, H. T. (1999). Comparison of measurement methods of osmotic adjustment in rice cultivars. Crop Sci. 39, 150-158.
Bacon, M. A., Davies, W. J., Mingo, D., and Wilkinson, S. (2002). "Root signals," in Plant Roots: The Hidden Half, 3rd Edn. eds Y. Waisel, A. Eshel, and U. Kafkafi (Monticello, NY: Marcel Dekker, Inc), 461-470.

Balota, M., Payne, W. A., Evett, S. R., and Lazar, M. D. (2007). Canopy temperature depression sampling to assess grain yield and genotypic differentiation in winter wheat. Crop Sci. 47, 1518-1529.

Bänziger, M., Setimela, P. S., Hodson, D., and Vivek, B. (2006). Breeding for improved abiotic stress tolerance in maize adapted to southern Africa. Agric. Water Manage. 80, 212-224.

Barbour, M. M., Fischer, R. A., Sayre, K. D., and Farquhar, G. D. (2000). Oxygen isotope ratio of leaf and grain material correlates with stomatal conductance and grain yield in irrigated wheat. Aust. J. Plant Physiol. 27, 625-637.

Barnabas, B., Jager, K., and Feher, A. (2008). The effect of drought and heat stress on reproductive processes in cereals. Plant Cell Environ. 31, 11-38.

Bartels, D., Ditzer, A., and Furini, A. (2006). What can we learn from resurrection plants? in Drought Adaptation in Cereals, ed J.-M. Ribaut (Binghamton, NY: The Haworth Press, Inc), 599-622.

Basu, P. S., Ali, M., and Chaturvedi, S. K. (2007). Osmotic adjustment increases water uptake, remobilization of assimilates and maintains photosynthesis in chickpea under drought. Indian J. Exp. Biol. 45, 261-267. 
Bengough, A. G., Bransby, M. F., Hans, J., McKenna, S. J., Roberts, T. J., and Valentine, T. A. (2006). Root responses to soil physical conditions; growth dynamics from field to cell. J. Exp. Bot. 57, 437-447.

Bengough, A. G., Gordon, D. C., AlMenaie, H., Ellis, R. P., Allan, D., Keith, R., Thomas, W. T. B., and Forster, B. P. (2004). Gel observation chamber for rapid screening of root traits in cereal seedlings. Plant Soil 262, 63-70.

Bernardo, R. (2004). What proportion of declared QTL in plants are false? Theor. Appl. Genet. 109, 419-424.

Bernardo, R. (2008). Molecular markers and selection for complex traits in plants: learning from the last 20 years. Crop Sci. 48, 1649-1664.

Bernardo, R. (2009). Genomewide selection for rapid introgression of exotic germplasm in maize. Crop Sci. 49, 419-425.

Bernardo, R., and Yu, J. M. (2007). Prospects for genomewide selection for quantitative traits in maize. Crop Sci. 47, 1082-1090.

Bernier, J., Kumar, A., Ramaiah, V., Spaner, D., and Atlin, G. (2007). A large-effect QTL for grain yield under reproductive-stage drought stress in upland rice. Crop Sci. 47, 507-518.

Bernier, J., Serraj, R., Kumar, A., Venuprasad, R., Impa, S., Gowda, R. P. V., Oane, R., Spaner, D., and Atlin, G. (2009). The large-effect droughtresistance QTL qtl12.1 increases water uptake in upland rice. Field Crops Res. 110, 139-146.

Beverly, R. B. (1996). Video image analysis as a nondestructive measure of plant vigor for precision agriculture. Commun. Soil Sci. Plant Anal. 27, 607-614.

Blanc, G., Charcosset, A., Mangin, B., Gallais, A., and Moreau, L. (2006). Connected populations for detecting quantitative trait loci and testing for epistasis: an application in maize. Theor. Appl. Genet. 113, 206-224.

Blanc, G., Charcosset, A., Veyrieras, J. B., Gallais, A., and Moreau, L. (2008). Marker-assisted selection efficiency in multiple connected populations: a simulation study based on the results of a QTL detection experiment in maize. Euphytica 161, 71-84.

Blouin, M., Barot, S., and Roumet, C. (2007). A quick method to determine root biomass distribution in diameter classes. Plant Soil 290, 371-381.

Blum, A. (1988). Breeding for Stress Environments. Boca Raton: CRC Press, 245.
Blum, A. (1996). Crop responses to drought and the interpretation of adaptation. Plant Growth Regul. 20, 135-148.

Blum, A. (1998). Improving wheat grain filling under stress by stem reserve mobilization. Euphytica 100, $77-83$.

Blum, A. (2005). Drought resistance, water-use efficiency, and yield potential-are they compatible, dissonant, or mutually exclusive? Aust. J. Agric. Res. 56, 1159-1168.

Blum, A. (2006). "Drought adaptation in cereal crops: a prologue," in Drought Adaptation in Cereals, ed J.-M. Ribaut (Binghamton, NY: The Haworth Press, Inc), 3-15.

Blum, A. (2009). Effective use of water (EUW) and not water-use efficiency (WUE) is the target of crop yield improvement under drought stress. Field Crops Res. 112, 119-123.

Blum, A. (2011). Plant Breeding for Water-Limited Environments. New York, NY: Springer.

Blum, A., Mayer, J., and Gozlan, G. (1982). Infrared thermal sensing of plant canopies as a screening technique for dehydration avoidance in wheat. Field Crops Res. 5, 137-146.

Blum, A., Munns, R., Passioura, J. B., and Turner, N. C. (1996). Genetically engineered plants resistant to soil drying and salt stress: how to interpret osmotic relations? Plant Physiol. 110, 1051-1053.

Blum, A., Zhang, J. X., and Nguyen, H. T. (1999). Consistent differences among wheat cultivars in osmotic adjustment and their relationship to plant production. Field Crops Res. 64, 287-291.

Bohnert, H. J., Gong, Q. Q., Li, P. H., and Ma, S. S. (2006). Unraveling abiotic stress tolerance mechanismsgetting genomics going. Curr. Opin. Plant Biol. 9, 180-188.

Bolaños, J., and Edmeades, G. O (1993). Eight cycles of selection for drought tolerance in lowland tropical maize. 2. Responses in reproductive behavior. Field Crops Res. 31, 253-268.

Bolaños, J., and Edmeades, G. O. (1996). The importance of the anthesis-silking interval in breeding for drought tolerance in tropical maize. Field Crops Res. 48, 65-80.

Borlaug, N. E. (2007). Sixty-two years of fighting hunger: personal recollections. Euphytica 157, 287-297.

Borlaug, N. E., and Dowswell, C. R. (2005). "Feeding a world of ten billion people: a 21 st century challenge," in Proceedings of the International Congress: In the Wake of the Double Helix: From the Green Revolution to the Gene Revolution, eds R. Tuberosa, R. L. Phillips, and M. Gale (Bologna, Italy: Avenue Media) 27-31 May, 3-23.

Borrell, A., Hammer, G., and Van Oosterom, E. (2001). Stay-green: a consequence of the balance between supply and demand for nitrogen during grain filling? Ann. Appl. Biol. 138, 91-95.

Bovina, R., Talamè, V., Ferri, M., Tuberosa, R., Chmielewska, B., Szarejko, I., and Sanguineti, M. C. (2011). Identification of root morphology mutants in barley. Plant Genet. Resour. 9, 357-360.

Boyer, J. S. (1995). Measuring the Water Status of Plants and Soils. London, UK: Academic Press, 178.

Boyer, J. S., James, R. A., Munns, R., Condon, T. A. G., and Passioura, J. B. (2008). Osmotic adjustment leads to anomalously low estimates of relative water content in wheat and barley. Funct. Plant Biol. 35, 1172-1182.

Boyer, J. S., and Westgate, M. E. (2004). Grain yields with limited water. J. Exp. Bot. 55, 2385-2394.

Bray, E. A. (2002). Abscisic acid regulation of gene expression during water-deficit stress in the era of the Arabidopsis genome. Plant Cell Environ. 25, 153-161.

Brennan, J. P., Condon, A. G., Van Ginkel, M., and Reynolds, M. P. (2007). An economic assessment of the use of physiological selection for stomatal aperture-related traits in the CIMMYT wheat breeding programme. J. Agric. Sci. 145, 187-194.

Buckler, E. S., Holland, J. B., Bradbury, P. J., Acharya, C. B., Brown, P. J., Browne, C., Ersoz, E., FlintGarcia, S., Garcia, A., Glaubitz, J. C., Goodman, M. M., Harjes, C., Guill, K., Kroon, D. E., Larsson, S., Lepak, N. K., Li, H. H., Mitchell, S. E., Pressoir, G., Peiffer, J. A., Rosas, M. O., Rocheford, T. R., Romay, M. C., Romero, S., Salvo, S., Villeda, H. S., da Silva, H. S., Sun, Q. Tian, F., Upadyayula, N., Ware, D., Yates, H., Yu, J. M., Zhang, Z. W., Kresovich, S., and McMullen, M. D. (2009). The genetic architecture of maize flowering time. Science 325 , 714-718.

Burgueno, J., Crossa, J., Cornelius, P. L., and Yang, R. C. (2008). Using factor analytic models for joining environments and genotypes without crossover genotype $\times$ environment interaction. Crop Sci. 48, 1291-1305.

Cairns, J. E., Audebert, A., Townend, J., Price, A. H., and Mullins, C. E. (2004). Effect of soil mechanical impedance on root growth of two rice varieties under field drought stress. Plant Soil 267, 309-318.

Cairns, J. E., Impa, S. M., O’Toole, J. C., Jagadish, S. V. K., and Price, A. H. (2011). Influence of the soil physical environment on rice (Oryza sativa $\mathrm{L}$.) response to drought stress and its implications for drought research. Plant Genet. Resour. 121, 303-310.

Cairns, J. E., Sonder, K., Zaidi, P. H., Verhulst, N., Mahuku, G., Babu, R., Nair, S. K., Das, B., Govaerts, B., Vinayan, M. T., Rashid, Z., Noor, J. J., Devi, P., Vicente, F. S., and Prasanna, B. M. (2012). Maize production in a changing climate: impacts, adaptation, and mitigation strategies. Adv. Agron. 114, 1-58.

Campillo, C., Prieto, M. H., Daza, C., Monino, M. J., and Garcia, M. I. (2008). Using digital images to characterize canopy coverage and light interception in a processing tomato crop. Hortscience 43, 1780-1786.

Campos, H., Cooper, M., Edmeades, G. O., Loffler, C., Schussler, J. R., and Ibanez, M. (2006). Changes in drought tolerance in maize associated with fifty years of breeding for yield in the US corn belt. Maydica 51, 369-381.

Casadesus, J., Kaya, Y., Bort, J., Nachit, M. M., Araus, J. L., Amor, S., Ferrazzano, G., Maalouf, F., Maccaferri, M., Martos, V., Ouabbou, H., and Villegas, D. (2007). Using vegetation indices derived from conventional digital cameras as selection criteria for wheat breeding in water-limited environments. Ann. Appl. Biol. 150, 227-236.

Cayci, G., Heng, L. K., Ozturk, H. S., Suerek, D., Kutuk, C., and Saglam, M. (2009). Crop yield and water use efficiency in semi-arid region of Turkey. Soil Till. Res. 103, 65-72.

Ceccarelli, S., and Grando, S. (1996). Drought as a challenge for the plant breeder. Plant Growth Regul. 20, 149-155.

Chaerle, L., Leinonen, I., Jones, H. G., and Van der Straeten, D. (2007). Monitoring and screening plant populations with combined thermal and chlorophyll fluorescence imaging. J. Exp. Bot. 58, 773-784.

Chapman, S. C., and Edmeades, G. O. (1999). Selection improves drought tolerance in tropical maize populations: II. Direct and correlated responses among secondary traits. Crop Sci. 39, 1315-1324.

Chapman, S. C., Chakraborty, S., Dreccer, M. F., and Howden, S. M. (2012). Plant adaptation to climate change-opportunities and priorities 
in breeding. Crop Pasture Sci. 63, 251-268.

Chapman, S., Cooper, M., Podlich, D., and Hammer, G. (2003). Evaluating plant breeding strategies by simulating gene action and dryland environment effects. Agron. J. 95, 99-113.

Chapuis, R., Delluc, C., Debeuf, R., Tardieu, F., and Welcker, C. (2012). Resiliences to water deficit in a phenotyping platform and in the field: how related are they in maize? Eur. J. Agron. 42, 59-67.

Chavarria-Krauser, A., Nagel, K. A., Palme, K., Schurr, U., Walter, A., and Scharr, H. (2008). Spatiotemporal quantification of differential growth processes in root growth zones based on a novel combination of image sequence processing and refined concepts describing curvature production. New Phytol. 177, 811-821.

Chaves, M. M., and Oliveira, M. M. (2004). Mechanisms underlying plant resilience to water deficits: prospects for water-saving agriculture. J. Exp. Bot. 55, 2365-2384.

Chen, J., Chang, S. X., and Anyia, A. O. (2012). Quantitative trait loci for water-use efficiency in barley (Hordeum vulgare L.) measured by carbon isotope discrimination under rain-fed conditions on the Canadian Prairies. Theor. Appl. Genet. 125, 71-90.

Chenu, K., Chapman, S. C., Hammer, G. L., McLean, G., Salah, H. B. H., and Tardieu, F. (2008). Shortterm responses of leaf growth rate to water deficit scale up to whole-plant and crop levels: an integrated modelling approach in maize. Plant Cell Environ. 31, 378-391.

Chimenti, C. A., Marcantonio, M., and Hall, A. J. (2006). Divergent selection for osmotic adjustment results in improved drought tolerance in maize (Zea mays L.) in both early growth and flowering phases. Field Crops Res. 95, 305-315.

Clark, R. T., MacCurdy, R. B., Jung, J. K., Shaff, J. E., McCouch, S. R., Aneshansley, D. J., and Kochian, L. V. (2011). Threedimensional root phenotyping with a novel imaging and software platform. Plant Physiol. 156, 455-465.

Collins, N. C., Tardieu, F., and Tuberosa, R. (2008). Quantitative trait loci and crop performance under abiotic stress: where do we stand? Plant Physiol. 147, 469-486.

Cominelli, E., Galbiati, M., Vavasseur, A., Conti, L., Sala, T., Vuylsteke, M., Leonhardt, N., Dellaporta, S. L., and Tonelli, C. (2005). A guard-cell-specific MYB transcription factor regulates stomatal movements and plant drought tolerance. Curr. Biol. 15, 1196-1200.

Condon, A. G., Farquar, G. D., Rebetzke, G. J., and Richards, R. A. (2006). "The application of carbon isotope discrimination in cereal improvement for waterlimited environments," in Drought Adaptation in Cereals, ed J.-M. Ribaut (Binghamton, NY: The Haworth Press, Inc), 171-219.

Condon, A. G., Farquar, G. D., and Richards, R. A. (1990). Genotypic variation in carbon isotope discrimination and transpiration efficiency in wheat. Leaf gas exchange and whole plant studies. Aust. J. Plant Physiol. 17, 9-22.

Condon, A. G., Richards, R. A., and Farquhar, G. D. (1993). Relationships between carbon isotope discrimination, water use efficiency and transpiration efficiency for dryland wheat. Aust. J. Agric. Res. 44, 1693-1711.

Condon, A. G., Richards, R. A., Rebetzke, G. J., and Farquhar, G. D. (2002). Improving intrinsic water-use efficiency and crop yield. Crop Sci. 42, 122-131.

Condon, A. G., Richards, R. A., Rebetzke, G. J., and Farquhar, G. D. (2004). Breeding for high water-use efficiency. J. Exp. Bot. 55, 2447-2460.

Cooper, M., Podlich, D. W., and Luo, L. (2007). "Modeling QTL effects and MAS in plant breeding," in Genomics-assisted crop improvement. Genomics approaches and platforms, Vol. 1, eds R. K. Varshney and R. Tuberosa (Dordrecht, The Netherlands: Springer), 57-95

Cooper, M., van Eeuwijk, F. A. Hammer, G. L., Podlich, D. W., and Messina, C. (2009). Modeling QTL for complex traits: detection and context for plant breeding. Curr. Opin. Plant Biol. 12, 231-240.

Courtois, B., Ahmadi, N., Khowaja, F., Price, A. H., Rami, J. F., Frouin, J., Hamelin, C., and Ruiz, M (2009). Rice root genetic architecture: meta-analysis from a drought QTL database. Rice 2, 115-128.

Courtois, B., Shen, L., Petalcorin, W., Carandang, S., Mauleon, R., and Li, Z. (2003). Locating QTLs controlling constitutive root traits in the rice population IAC $165 \times \operatorname{Co} 39$. Euphytica 134, 335-345.

Crossa, J., Burgueno, J., Dreisigacker, S., Vargas, M., Herrera-Foessel, S. A., Lillemo, M., Singh, R. P., Trethowan, R., Warburton, M., Franco, J., Reynolds, M., Crouch, J. H., and Ortiz, R. (2007).
Association analysis of historical bread wheat germplasm using additive genetic covariance of relatives and population structure. Genetics 177, 1889-1913.

Davies, W. J., Bacon, M. A., Thompson, D. S., Sobeih, W., and Rodriguez, L. G. (2000). Regulation of leaf and fruit growth in plants growing in drying soil: exploitation of the plants' chemical signalling system and hydraulic architecture to increase the efficiency of water use in agriculture. J. Exp. Bot. 51, 1617-1626.

de Dorlodot, S., Bertin, P., Baret, P., and Draye, X. (2005). Scaling up quantitative phenotyping of root system architecture using a combination of aeroponics and image analysis. Aspects Appl. Biol. 73, 41-54.

de Dorlodot, S., Forster, B., Pages, L., Price, A., Tuberosa, R., and Draye, X. (2007). Root system architecture: opportunities and constraints for genetic improvement of crops. Trends Plant Sci. 12, 474-481.

Degenkolbe, T., Do, P. T., Zuther, E. Repsilber, D., Walther, D., Hincha, D. K., and Kohl, K. I. (2009) Expression profiling of rice cultivars differing in their tolerance to longterm drought stress. Plant Mol. Biol. 69, 133-153.

Deikman, J., Petracek, M., and Heard, J. E. (2012). Drought tolerance through biotechnology: improving translation from the laboratory to farmers' fields. Curr. Opin. Biotechnol. 23, 243-250.

Deokar, A. A., Kondawar, V., Jain, P. K., Karuppayil, S. M., Raju, N. L., Vadez, V., Varshney, R. K., and Srinivasan, R. (2011). Comparative analysis of expressed sequence tags (ESTs) between drought-tolerant and-susceptible genotypes of chickpea under terminal drought stress. BMC Plant Biol. 11, 70. doi: 10.1186/1471-2229-11-70

De Smet, I., White, P. J., Bengough, A. G., Dupuy, L., Parizot, B., Casimiro, I., Heidstra, R., Laskowski, M., Lepetit, M., Hochholdinger, F., Draye, X., Zhang, H. M., Broadley, M. R., Peret, B., Hammond, J. P., Fukaki, H., Mooney, S., Lynch, J. P., Nacry, P., Schurr, U., Laplaze, L., Benfey, P., Beeckman, T., and Bennett, M. (2012). Analyzing lateral root development: how to move forward. Plant Cell 24, 15-20.

Di Bianco, D., Thiyagarajan, K., Latini, A., Cantale, C., Felici, F., and Galeffi, P. (2011). Exploring the genetic diversity of the DRF1 gene in durum wheat and its wild relatives. Plant Genet. Res. 9, 247-250.

Dingkuhn, M., Luquet, D., Quilot, B., and de Reffye, P. (2005). Environmental and genetic control of morphogenesis in crops: towards models simulating phenotypic plasticity. Aust. J. Agric. Res. 56, 1289-1302.

Distelfeld, A., Li, C., and Dubcovsky, J. (2009). Regulation of flowering in temperate cereals. Curr. Opin. Plant Biol. 12, 178-184.

Dixit, S., Swamy, B. P. M., Vikram, P., Ahmed, H. U., Cruz, M. T. S., Amante, M., Atri, D., Leung, H., and Kumar, A. (2012). Fine mapping of QTLs for rice grain yield under drought reveals sub-QTLs conferring a response to variable drought severities. Theor. Appl. Genet. 125, 155-169.

Dreccer, A. F., Borgognone, A. G., Ogbonnaya, F. C., Trethowan, R. M. and Winter, B. (2007). CIMMYTselected derived synthetic bread wheats for rainfed environments: yield evaluation in Mexico and Australia. Field Crops Res. 100, 218-228.

Duvick, D. N. (2005). The contribution of breeding to yield advances in maize (Zea mays L.). Adv. Agron. 86, 83-145.

Edmeades, G. O., McMaster, G. S., White, J. W., and Campos, $\mathrm{H}$. (2004). Genomics and the physiologist: bridging the gap between genes and crop response. Field Crops Res. 90, 5-18.

Ehdaie, B., Alloush, G. A., and Waines, J. G. (2008). Genotypic variation in linear rate of grain growth and contribution of stem reserves to grain yield in wheat. Field Crops Res. 106, 34-43.

Elsayed, S., Mistele, B., and Schmidhalter, U. (2011). Can changes in leaf water potential be assessed spectrally? Funct. Plant Biol. 38, 523-533.

Ergen, N. Z., and Budak, H. (2009). Sequencing over 13, 000 expressed sequence tags from six subtractive cDNA libraries of wild and modern wheats following slow drought stress. Plant Cell Environ. 32, 220-236.

Falconer, D. S. (1981). Introduction to Quantitative Genetics. 2nd Edn. London: Longman, 340.

Fan, X. W., Li, F. M., Xiong, Y. C., An, L. Z., and Long, R. J. (2008). The cooperative relation between non-hydraulic root signals and osmotic adjustment under water stress improves grain formation for spring wheat varieties. Physiol. Plantarum 132, 283-292. 
Fares, A., and Polyakov, V. (2006). Advances in crop water management using capacitive water sensors. Adv. Agron. 90, 43-77.

Farooq, M., Wahid, A., Kobayashi, N., Fujita, D., and Basra, S. M. A. (2009). Plant drought stress: effects, mechanisms and management. Agron. Sustain. Dev. 29, 185-212.

Fernie, A. R., and Schauer, N. (2009). Metabolomics-assisted breeding: a viable option for crop improvement? Trends Genet. 25, 39-48.

Ferrio, J. P., Mateo, M. A., Bort, J., Abdalla, O., Voltas, J., and Araus, J. L. (2007). Relationships of grain D13C and D18O with wheat phenology and yield under waterlimited conditions. Ann. Appl. Biol. 150, 207-215.

Feuillet, C., Langridge, P., and Waugh, R. (2008). Cereal breeding takes a walk on the wild side. Trends Genet. 24, 24-32.

Feuillet, C., Leach, J. E., Rogers, J., Schnable, P. S., and Eversole, K. (2011). Crop genome sequencing: lessons and rationales. Trends Plant Sci. 16, 77-88.

Fiorani, F., Rascher, U., Jahnke, S., and Schurr, U. (2012). Imaging plants dynamics in heterogenic environments. Curr. Opin. Biotech. 23, 227-235.

Fischer, K. S., Lafitte, R., Fukai, S., Atlin, G., and Hardy, B. (2003). Breeding Rice for Drought-Prone Environments. Los Baños, The Philippines: The International Rice Research Institute, 98.

Fischer, R. A., Rees, D., Sayre, K. D., Lu, Z. M., Condon, A. G., and Larque Saavedra, A. (1998). Wheat yield progress associated with higher stomatal conductance and photosynthetic rate, and cooler canopies. Crop Sci. 38, 1467-1475.

Forde, G. B. (2009). Is it good noise? The role of developmental instability in the shaping of a root system. J. Exp. Bot. 60, 3989-4002.

Forster, B. P., Ellis, R. P., Thomas, W. T. B., Newton, A. C., Tuberosa, R., This, D., El Enein, R. A., Bahri, M. H., and Ben Salem, M. (2000). The development and application of molecular markers for abiotic stress tolerance in barley. J. Exp. Bot. 51, 19-27.

Forster, B. P., Thomas, W. T. B., and Chloupek, O. (2005). Genetic controls of barley root systems and their associations with plant performance. Aspects Appl. Biol. 73, 199-204.

Frascaroli, E., Canè, M. A., Pè, M. E., Pea, G., Morgante, M., and Landi, P. (2009). QTL detection in maize testcross progenies as affected by related and unrelated testers. Theor Appl. Genet. 118, 993-1004.

Frascaroli, E., and Landi, P. (1996). Pollen effects of selection in maize for the reaction to abscisic acid applied to silks. Maydica 41, 301-306.

Frascaroli, E., and Tuberosa, R. (1993). Effect of abscisic acid on pollen germination and tube growth of maize genotypes. Plant Breed. 110, 250-254.

Fukai, S., and Cooper, M. (1995). Development of droughtresistant cultivars using physio-morphological traits in rice. Field Crops Res. 40, 67-86.

Furbank, R. T., and Tester, M. (2011). Phenomics - technologies to relieve the phenotyping bottleneck. Trends Plant Sci. 16, 635-644.

Gallais, A., and Hirel, B. (2004). An approach to the genetics of nitrogen use efficiency in maize. J. Exp. Bot. 55, 295-306.

Ganal, M. W., Altmann, T., and Röder, M. S. (2009). SNP identification in crop plants. Curr. Opin. Plant Biol. $12,211-217$.

Gao, Y. M., and Zhu, J. (2007) Mapping QTLs with digenic epistasis under multiple environments and predicting heterosis based on QTL effects. Theor. Appl. Genet.115, 325-333.

Gerald, J. N. F., Lehti-Shiu, M. D., Ingram, P. A., Deak, K. I., Biesiada, T., and Malamy, J. E. (2006). Identification of quantitative trait loci that regulate Arabidopsis root system size and plasticity. Genetics $172,485-498$.

Ghimire, K. H., Quiatchon, L. A., Vikram, P., Swamy, B. P. M., Dixit, S., Ahmed, H., Hernandez, J. E., Borromeo, T. H., and Kumar, A. (2012). Identification and mapping of a QTL ( $q$ DTY1.1) with a consistent effect on grain yield under drought. Field Crops Res. 131, 88-96.

Giuliani, S., Sanguineti, M. C., Tuberosa, R., Bellotti, M., Salvi, S., and Landi, P. (2005). Root-ABA1, a major constitutive QTL, affects maize root architecture and leaf ABA concentration at different water regimes. J. Exp. Bot. 56, 3061-3070.

Gonzalez, A., Martin, I., and Ayerbe, L. (2008). Yield and osmotic adjustment capacity of barley under terminal water-stress conditions. J. Agron. Crop Sci. 194, 81-91.

Grando, S., and Ceccarelli, S. (1995). Seminal root morphology and coleoptile length in wild (Hordeum vulgare ssp. spontaneum) and cultivated (Hordeum vulgare ssp. vulgare) barley. Euphytica 86, 73-80.

Granier, C., Aguirrezabal, L., Chenu, K., Cookson, S. J., Dauzat, M., Hamard, P., Thioux, J. J., Rolland, G., Bouchier-Combaud, S., Lebaudy, A., Muller, B. Simonneau, T., and Tardieu, F. (2006). PHENOPSIS, an automated platform for reproducible phenotyping of plant responses to soil water deficit in Arabidopsis thaliana permitted the identification of an accession with low sensitivity to soil water deficit. New Phytol. 169, 623-635.

Grant, O. M., Chaves, M. M., and Jones, H. G. (2006). Optimizing thermal imaging as a technique for detecting stomatal closure induced by drought stress under greenhouse conditions. Physiol. Plantarum 127, 507-518.

Grant, O. M., Tronina, L., Jones, H. G., and Chaves, M. M. (2007) Exploring thermal imaging variables for the detection of stress responses in grapevine under different irrigation regimes. J. Exp. Bot. 58, 815-825.

Gray, S. B., Dermody, O., and DeLucia, E. H. (2010). Spectral reflectance from a soybean canopy exposed to elevated $\mathrm{CO}_{2}$ and $\mathrm{O}_{3}$. J. Exp. Bot. 61 , 4413-4422.

Guo, P. G., Baum, M., Varshney, R. K., Graner, A., Grando, S., and Ceccarelli, S. (2008). QTLs for chlorophyll and chlorophyll fluorescence parameters in barley under post-flowering drought. Euphytica $163,203-214$

Gur, A., and Zamir, D. (2004). Unused natural variation can lift yield barriers in plant breeding. PLoS Biol. 2:e245. doi: 10.1371/journal.pbio.0020245

Gutierrez, M., Reynolds, M. P., and Klatt, A. R. (2010). Association of water spectral indices with plant and soil water relations in contrasting wheat genotypes. J. Exp. Bot. 61, 3291-3303.

Hamada, A., Nitta, M., Nasuda, S., Kato, K., Fujita, M., Matsunaka, H., and Okumoto, Y. (2012). Novel QTLs for growth angle of seminal roots in wheat (Triticum aestivum L.). Plant Soil 354, 395-405.

Hammer, G., Cooper, M., Tardieu, F., Welch, S., Walsh, B., van Eeuwijk, F., Chapman, S., and Podlich, D. (2006). Models for navigating biological complexity in breeding improved crop plants. Trends Plant Sci. 11, 587-593.

Hammer, G. L., Chapman, S., van Oosterom, E., and Podlich, D. W.
(2005). Trait physiology and crop modelling as a framework to link phenotypic complexity to underlying genetic systems. Aust. J. Agric. Res. 56, 947-960.

Hammer, G. L., Dong, Z. S., McLean, G., Doherty, A., Messina, C., Schusler, J., Zinselmeier, C., Paszkiewicz, S., and Cooper, M. (2009). Can changes in canopy and/or root system architecture explain historical maize yield trends in the US corn belt? Crop Sci. 49, 299-312.

Hammer, G. L., Sinclair, T. R. Chapman, S. C., and van Oosterom, E. (2004). On systems thinking, systems biology, and the in silico plant. Plant Physiol. 134, 909-911.

Hao, Z. F., Li, X. H., Xie, C. X., Li, M. S., Zhang, D. G., Bai, L., and Zhang, S. H. (2008). Two consensus quantitative trait loci clusters controlling anthesis-silking interval, ear setting and grain yield might be related with drought tolerance in maize. Ann. Appl. Biol. 153, 73-83.

Hargreaves, C. E., Gregory, P. J., and Bengough, A. G. (2009). Measuring root traits in barley (Hordeum vulgare ssp. vulgare and ssp. spontaneum) seedlings using gel chambers, soil sacs and X-ray microtomography. Plant Soil 316 , 285-297.

Harris, K., Subudhi, P. K., Borrell, A., Jordan, D., Rosenow, D., Nguyen, H., Klein, P., Klein, R., and Mullet, J. (2007). Sorghum stay-green QTL individually reduce post-flowering drought-induced leaf senescence. $J$. Exp. Bot. 58, 327-338.

Hatfield, J. L., Gitelson, A. A., Schepers, J. S., and Walthall, C. L. (2008). Application of spectral remote sensing for agronomic decisions. Agron. J. 100, S117-S131.

Heffner, E. L., Sorrells, M. E., and Jannink, J. L. (2009). Genomic selection for crop improvement. Crop Sci. 49, 1-12.

Heinemann, A. B., Dingkuhn, M., Luquet, D., Combres, J. C., and Chapman, S. (2008). Characterization of drought stress environments for upland rice and maize in central Brazil. Euphytica $162,395-410$

Henry, A., Gowda, V. R. P., Torres, R. O., McNally, K. L., and Serraj, R. (2011). Variation in root system architecture and drought response in rice (Oryza sativa): phenotyping of the OryzaSNP panel in rainfed lowland fields. Field Crops Res. 120, 205-214.

Himmelbauer, M. L., Loiskandl, W., and Kastanek, F. (2004). Estimating length, average diameter and surface 
area of roots using two different image analyses systems. Plant Soil 260, 111-120.

Hiremath, P. J., Farmer, A., Cannon, S. B., Woodward, J., Kudapa, H., Tuteja, R., Kumar, A. Bhanuprakash, A., Mulaosmanovic, B., Gujaria, N., Krishnamurthy, L., Gaur, P. M., Kavikishor, P. B., Shah, T., Srinivasan, R., Lohse, M., Xiao, Y., Town, C. D., Cook, D. R., May, G. D., and Varshney, R. K. (2011). Large-scale transcriptome analysis in chickpea (Cicer arietinum L.), an orphan legume crop of the semiarid tropics of Asia and Africa. Plant Biotechnol. J. 9, 922-931.

Hochholdinger, F., and Tuberosa, R. (2009). Genetics and genomics of root architecture in maize. Curr. Opin. Plant Biol. 12, 172-177.

Hoogenboom, G., White, J. W., and Messina, C. D. (2004). From genome to crop: integration through simulation modeling. Field Crops Res. 90, 145-163.

Hose, E., Clarkson, D. T., Steudle, E., Schreiber, L., and Hartung, W. (2001). The exodermis: a variable apoplastic barrier. J. Exp. Bot. 52, 2245-2264.

Houle, D., Govindaraju, D. R., and Omholt, S. (2010). Phenomics: the next challenge. Nature Rev. Genet. 11, 855-866.

Hund, A., Reimer, R., and Messmer, R. (2011). A consensus map of QTLs controlling the root length of maize. Plant Soil 344, 143-158.

Ito, K., Tanakamaru, K., Morita, S., Abe, J., and Inanaga, S. (2006). Lateral root development, including responses to soil drying, of maize (Zea mays) and wheat (Triticum aestivum) seminal roots. Physiol. Plantarum 127, 260-267.

Iyer-Pascuzzi, A. S., Symonova, O., Mileyko, Y., Hao, Y. L., Belcher, H., Harer, J., Weitz, J. S., and Benfey, P. N. (2010). Imaging and analysis platform for automatic phenotyping and trait ranking of plant root systems. Plant Physiol. 152, 1148-1157.

Izanloo, A., Condon, A. G., Langridge, P., Tester, M., and Schnurbusch, T. (2008). Different mechanisms of adaptation to cyclic water stress in two South Australian bread wheat cultivars. J. Exp. Bot. 59, 3327-3346.

Jagadish, K. S. V., Cairns, J. E., Kumar, A., Somayanda, I. M., and Craufurd, P. Q. (2011). Does susceptibility to heat stress confound screening for drought tolerance in rice? Funct. Plant Biol. 38, 261-269.

Jannink, J. L. (2007). Identifying quantitative trait locus by genetic background interactions in association studies. Genetics 176, 553-561.

Jansen, R. C., Tesson, B. M., Fu, J., Yang, Y., and McIntyre, L. M. (2009). Defining gene and QTL networks. Curr. Opin. Plant Biol. 12, 241-246.

Jenks, M. A., Hasegawa, P. M., and Mohan Jain, S. (eds.) (2007). Advances in Molecular Breeding Toward Drought and Salt Tolerant Crops. Dordrecht, The Netherlands: Springer, 817

Jiang, G. H., He, Y. Q., Xu, C. G. Li, X. H., and Zhang, Q. (2004). The genetic basis of stay-green in rice analyzed in a population of doubled haploid lines derived from an indica by japonica cross. Theor. Appl. Genet. 108, 688-698.

Johnson, M. G., Tingey, D. T., Phillips, D. L., and Storm, M. J. (2001) Advancing fine root research with minirhizotrons. Environ. Exp. Bot. 45, 263-289.

Johnson, W. C., Jackson, L. E., Ochoa, O., Peleman, J., St Clair, D. A., Michelmore, R. W., and van Wijk, R. (2000). Lettuce, a shallow-rooted crop, and Lactuca serriola, its wild progenitor, differ at QTL determining root architecture and deep soil water exploitation. Theor. Appl. Genet. 101, 1066-1073.

Jones, H. G. (2007). Monitoring plant and soil water status: established and novel methods revisited and their relevance to studies of drought tolerance. J. Exp. Bot. 58, 119-130.

Jones, H. G., Archer, N., Rotenberg, E., and Casa, R. (2003). Radiation measurement for plant ecophysiology. J. Exp. Bot. 54, 879-889.

Jones, H. G., Serraj, R., Loveys, B. R., Xiong, L. Z., Wheaton, A. and Price, A. H. (2009). Thermal infrared imaging of crop canopies for the remote diagnosis and quantification of plant responses to water stress in the field. Funct. Plant Biol. 36, 978-989.

Jongdee, B., Fukai, S., and Cooper, M. (2002). Leaf water potential and osmotic adjustment as physiological traits to improve drought tolerance in rice. Field Crops Res. 76, 153-163.

Kahinda, J. M., Lillie, E. S. B., Taigbenu, A. E., Taute, M., and Boroto, R. J. (2008). Developing suitability maps for rainwater harvesting in South Africa. Phys. Chem. Earth 33 788-99.

Kamoshita, A., Babu, R. C., Boopathi N. M., and Fukai, S. (2008). Phenotypic and genotypic analysis of drought-resistance traits for development of rice cultivars adapted to rainfed environments. Field Crops Res. 109, 1-23.
Kato, Y., Kamoshita, A., Yamagishi, J., Imoto, H., and Abe, J. (2007). Growth of rice (Oryza sativa L.) cultivars under upland conditions with different levels of water supply. 3. Root system development, soil moisture change and plant water status. Plant Prod. Sci. 10, 3-13.

Kholova, J., Hash, C. T., Kakkera A., Kocova, M., and Vadez, V. (2010a). Constitutive waterconserving mechanisms are corre lated with the terminal drought tolerance of pearl millet [Pennisetum glaucum (L.) R. Br.]. J. Exp. Bot. 61, 369-377.

Kholova, J., Hash, C. T., Kumar, P. L., Yadav, R. S., Kocova, M., and Vadez, V. (2010b). Terminal droughttolerant pearl millet [Pennisetum glaucum (L.)] R. Br. have high leaf $\mathrm{ABA}$ and limit transpiration at high vapour pressure deficit. J. Exp. Bot. 61, 1431-1440.

Khowaja, F. S., and Price, A. H. (2008) QTL mapping rolling, stomatal conductance and dimension traits of excised leaves in the Bala $\times$ Azucena recombinant inbred population of rice. Field Crops Res. 106, 248-257.

Kimura, K., Kikuchi, S., and Yamasaki, S. (1999). Accurate root length measurement by image analysis. Plant Soil 216, 117-127.

Kimurto, P. K., Kinyua, M. G., Birechl R., Korir, P. C., Njoka, E. M., and Njau, P. N. (2005). Root and shoot characteristics as selection criteria for drought tolerance in bread wheat (Triticum aestivum L.) at seedling stage under tropical environment. Discov. Innov. 17, 74-84.

King, C. A., Purcell, L. C., and Brye, K. R. (2009). Differential wilting among soybean genotypes in response to water deficit. Crop Sci. 49, 290-298.

Kirkham, M. B. (2004). Principles of Soil and Plant Water Relations. Burlington, MA: Elsevier Academic Press, 500.

Kota, R., Varshney, R. K., Prasad, M., Zhang, H., Stein, N., and Graner, A. (2008). EST-derived single nucleotide polymorphism markers for assembling genetic and physical maps of the barley genome. Funct. Integr. Genom. 8, 223-233.

Kumar, A., Bernier, J., Verulkar, S. Lafitte, H. R., and Atlin, G. N. (2008). Breeding for drought tolerance: direct selection for yield, response to selection and use of drought-tolerant donors in upland and lowland-adapted populations. Field Crops Res. 107, 221-231.

Kumar, A., and Singh, D. P. (1998). Use of physiological indices as a screening technique for drought tolerance in oilseed Brassica species. Ann. Bot. 81, 413-420.

Lafitte, H. R., and Edmeades, G. O. (1995). Stress tolerance in tropical maize is linked to constitutive changes in ear growth characteristics. Crop Sci. 35, 820-826.

Lafitte, H. R., Li, Z. K., Vijayakumar, C. H. M., Gao, Y. M., Shi, Y., Xu, J. L., Fu, B. Y., Ali, A. J., Domingo, J., Maghirang, R., Torres, R., and Mackill, D. (2006). Improvement of rice drought tolerance through backcross breeding: evaluation of donors and selection in drought nurseries. Field Crops Res. 97, 77-86.

Landi, P., Albrecht, B., Giuliani, M. M., and Sanguineti, M. C. (1998). Seedling characteristics in hydroponic culture and field performance of maize genotypes with different resistance to root lodging. Maydica 43, 111-116.

Landi, P., Conti, S., Gherardi, F., Sanguineti, M. C., and Tuberosa, R. (1995). Genetic analysis of leaf ABA concentration and of agronomic traits in maize hybrids grown under different water regimes. Maydica 40, 179-186.

Landi, P., Frascaroli, E., and Sanguineti, M. C. (2000). Correlated responses to selection for reaction to abscisic acid applied to silks in maize. Maydica 45, 113-116.

Landi, P., Giuliani, M. M., Darrah, L. L., Tuberosa, R., Conti, S., and Sanguineti, M. C. (2001a). Variability for root and shoot traits in a maize population grown in hydroponics and in the field and their relationships with vertical root pulling resistance. Maydica 46, 177-182.

Landi, P., Sanguineti, M. C., Conti, S. and Tuberosa, R. (2001b). Direct and correlated responses to divergent selection for leaf abscisic acid concentration in two maize populations. Crop Sci. 41, 335-344.

Landi, P., Giuliani, S., Salvi, S., Ferri, M., Tuberosa, R., and Sanguineti, M. C. (2010). Characterization of root-yield-1.06, a major constitutive QTL for root and agronomic traits in maize across water regimes. J. Exp. Bot. 61, 3553-3562.

Landi, P., Sanguineti, M. C., Darrah, L. L., Giuliani, M. M., Salvi, S., Conti, S., and Tuberosa, R. (2002). Detection of QTLs for vertical root pulling resistance in maize and overlap with QTLs for root traits in hydroponics and for grain yield under different water regimes. Maydica 47, 233-243.

Landi, P., Sanguineti, M. C., Liu, C., Li, Y., Wang, T. Y., Giuliani, S., Bellotti, M., Salvi, S., and Tuberosa, 
R. (2007). Root-ABAl QTL affects root lodging, grain yield, and other agronomic traits in maize grown under well-watered and waterstressed conditions. J. Exp. Bot. 58, 319-326.

Landi, P., Sanguineti, M. C., Salvi, S., Giuliani, S., Bellotti, M., Maccaferri, M., Conti, S., and Tuberosa, R. (2005). Validation and characterization of a major QTL affecting leaf ABA concentration in maize. Mol. Breed. 15, 291-303.

Langridge, P. (2005). "Molecular breeding of wheat and barley," in Proceedings of the International Congress: In the Wake of the Double Helix: From the Green Revolution to the Gene Revolution, eds R. Tuberosa, R. L. Phillips, and M. Gale (Bologna, Italy: Avenue Media), 27-31 May, 279-286.

Lebreton, C., Lazic-Jancic, V., Steed, A., Pekic, S., and Quarrie, S. A. (1995). Identification of QTL for drought responses in maize and their use in testing causal relationships between traits. J. Exp. Bot. 46, 853-865.

Leinonen, I., Grant, O. M., Tagliavia, C. P. P., Chaves, M. M., and Jones, H. G. (2006). Estimating stomatal conductance with thermal imagery. Plant Cell Environ. 29, 1508-1518.

Letort, V., Mahe, P., Cournede, P. H., De Reffye, P., and Courtois, B. (2008). Quantitative genetics and functional-structural plant growth models: simulation of quantitative trait loci detection for model parameters and application to potential yield optimization. Ann. Bot. 101, 1243-1254.

Leung, H. (2008). Stressed genomicsbringing relief to rice fields. Curr. Opin. Plant Biol. 11, 201-208.

Levitt, J. (1972). Responses of Plants to Environmental Stresses. New York, NY: Academic Press, 698.

Lippman, Z. B., Semel, Y., and Zamir, D. (2007). An integrated view of quantitative trait variation using tomato interspecific introgression lines. Curr. Opin. Genet. Dev. 17, 545-552.

Li, X. H., Liu, X. D., Li, M. S., and Zhang, S. H. (2003a). Identification of quantitative trait loci for anthesis-silking interval and yield components under drought stress in maize. Acta Bot. Sin. 45, 852-857.

Li, Z. K., Yu, S. B., Lafitte, H. R., Huang, N., Courtois, B., Hittalmani, S., Vijayakumar, C. H. M., Liu, G. F., Wang, G. C., Shashidhar, H. E., Zhuang, J. Y., Zheng, K. L., Singh, V. P., Sidhu, J. S., Srivantaneeyakul, S., and Khush, G. S. (2003b). QTL $\times$ environment interactions in rice. I. Heading date and plant height. Theor. Appl. Genet. 108, 141-153.

Lobell, D. B., Schlenker, W., and CostaRoberts, J. (2011). Climate trends and global crop production since 1980. Science 333, 616-620.

Lopes, M. S., Reynolds, M. P., JalalKamali, M. R., Moussa, M., Feltaous, Y., Tahir, I. S. A., Barma, N., Vargas, M., Mannes, Y., and Baum, M. (2012). The yield correlations of selectable physiological traits in a population of advanced spring wheat lines grown in warm and drought environments. Field Crops Res. 128, 129-136.

Ludlow, M. M., and Muchow, R. C. (1990). A critical evaluation of traits for improving crop yields in waterlimited environments. Adv. Agron. $43,107-153$.

Luo, L. J. (2010). Breeding for watersaving and drought-resistance rice (WDR) in China. J. Exp. Bot. 61, 3509-3517.

Lu, Y. L., Xu, J., Yuan, Z. M., Hao, Z. F., Xie, C. X., Li, X. H., Shah, T., Lan, H., Zhang, S. H., Rong, T. Z., and $\mathrm{Xu}, \mathrm{Y}$. B. (2012). Comparative LD mapping using single SNPs and haplotypes identifies QTL for plant height and biomass as secondary traits of drought tolerance in maize. Mol. Breed. 30, 407-418.

Lu, Y., Zhang, S., Shah, T., Xie, C., Hao, Z., Li, X., Farkhari, M., Ribaut, J.-M., Cao, M., Rong, T., and $\mathrm{Xu}$, Y. (2010). Joint linkagelinkage disequilibrium mapping is a powerful approach to detecting quantitative trait loci underlying drought tolerance in maize. Proc. Natl. Acad. Sci. U.S.A. 107 19585-19590.

Lynch, J. P. (2007). Roots of the second green revolution. Aust. J. Bot. $55,493-512$.

Maccaferri, M., Sanguineti, M. C., Corneti, S., Ortega, J. L. A., Ben Salem, M., Bort, J., DeAmbrogio, E., del Moral, L. F. G., Demontis, A., El-Ahmed, A., Maalouf, F., Machlab, H., Martos, V., Moragues, M., Motawaj, J., Nachit, M., Nserallah, N., Ouabbou, H., Royo, C., Slama, A., and Tuberosa, R. (2008). Quantitative trait loci for grain yield and adaptation of durum wheat (Triticum durum Desf.) across a wide range of water availability. Genetics 178, 489-511.

Maccaferri, M., Sanguineti, M. C., Demontis, A., El-Ahmed, A., de Moral, L. G., Maalouf, F., Nachit, M., Nserallah, N., Ouabbou, H., Rhouma, S., Royo, C., Villegas, D., and Tuberosa, R. (2011). Association mapping in durum wheat grown across a broad range of water regimes. J. Exp. Bot. 62, 409-438.

Mace, E. S., Singh, V., Van Oosterom, E. J., Hammer, G. L., Hunt, C. H., and Jordan, D. R. (2012). QTL for nodal root angle in sorghum (Sorghum bicolor L. Moench) colocate with QTL for traits associated with drought adaptation. Theor. Appl. Genet. 124, 97-109.

Mackill, D. J. (2006). "Breeding for resistance to abiotic stresses in rice: the value of quantitative trait loci," in Plant Breeding: The Arnel, $R$. Hallauer International Symposium, eds K. R. Lamkey and M. Lee (Ames, IA: Blackwell Publishing), 201-212.

Malosetti, M., Ribaut, J.-M., Vargas, M., Crossa, J., and van Eeuwijk, F. A. (2008). A multi-trait multienvironment QTL mixed model with an application to drought and nitrogen stress trials in maize (Zea mays L.). Euphytica 161, 241-257.

Mambelli, S., and Setter, T. L. (1998), Inhibition of maize endosperm cell division and endoreduplication by exogenously applied abscisic acid. Physiol. Plantarum 104, 266-272.

Manieri, J. M., Vaz, C. M. P., and De Maria, I. C. (2007). TDR spiral probe for moisture measurement in the soil profile. Revista Brasileira De Ciencia Do Solo 31, 191-198.

Manschadi, A. M., Christopher, J., Devoil, P., and Hammer, G. L. (2006). The role of root architectural traits in adaptation of wheat to water-limited environments. Funct. Plant Biol. 33, 823-837.

Manschadi, A. M., Christopher, J. T., Hammer, G. L., and Devoil, P. (2010). Experimental and modelling studies of drought-adaptive root architectural traits in wheat (Triticum aestivum L.). Plant Biosyst. 144, 458-462.

Marti, J., Bort, J., Slafer, G., and Araus, J. L. (2007). Can wheat yield be assessed by early measurements of NDVI? Ann. Appl. Biol. 150, 253-257.

Mathews, K. L., Malosetti, M., Chapman, S., McIntyre, L., Reynolds, M., Shorter, R., and van Eeuwijk, F. (2008). Multienvironment QTL mixed models for drought stress adaptation in wheat. Theor. Appl. Genet. 117, 1077-1091.

McBride, R., Candidoa, M., and Ferguson, J. (2008). Estimating root mass in maize genotypes using the electrical capacitance method. Arch. Agron. Soil Sci. 54, 215-226.

McLaughlin, J. E., and Boyer, J. S. (2004). Sugar-responsive gene expression, invertase activity, and senescence in aborting maize ovaries at low water potentials. Ann. Bot. 94, 675-689.

McLaughlin, J. E., and Boyer, J. S. (2007). Functional reversion to identify controlling genes in multigenic responses: analysis of floral abortion. J. Exp. Bot. 58, 267-277.

Merah, O. (2001). Potential importance of water status traits for durum wheat improvement under Mediterranean conditions. J. Agricul. Sci. 137, 139-145.

Merah, O., Deleens, E., Al Hakimi, A., and Monneveux, P. (2001). Carbon isotope discrimination and grain yield variations among tetraploid wheat species cultivated under contrasting precipitation regimes. J. Agron. Crop Sci. 186, 129-134.

Messina, C. D., Podlich, D., Dong, Z., Samples, M., and Cooper, M. (2011). Yield-trait performance landscapes: from theory to application in breeding maize for drought tolerance. J. Exp. Bot. 62, 855-868.

Messmer, R., Fracheboud, Y., Banziger, M., Vargas, M., Stamp, P., and Ribaut, J. M. (2009). Drought stress and tropical maize: QTLby-environment interactions and stability of QTLs across environments for yield components and secondary traits. Theor. Appl. Genet. 119, 913-930.

Mir, R. R., Zaman-Allah, M., Sreenivasulu, N., Trethowan, R., and Varshney, R. K. (2012). Integrated genomics, physiology and breeding approaches for improving drought tolerance in crops. Theor. Appl. Genet. 125, 625-645.

Mittler, R., and Blumwald, E. (2010). Genetic engineering for modern agriculture: challenges and perspectives. Annu. Rev. Plant Biol. 61, 443-462.

Mohamed, M. F., Keutgen, N., Tawfik, A. A., and Noga, G. (2002). Dehydration-avoidance responses of tepary bean lines differing in drought resistance. J. Plant Physiol. $159,31-38$

Moncada, P., Martinez, C. P., Borrero, J., Chatel, M., Gauch, H., Guimaraes, E., Tohme, J., and McCouch, S. R. (2001). Quantitative trait loci for yield and yield components in an Oryza sativa $\times$ Oryza rufipogon $\mathrm{BC}_{2} \mathrm{~F}_{2}$ population evaluated in an upland environment. Theor. Appl. Genet. $102,41-52$

Mondini, L., Nachit, M. M., Porceddu, E., and Pagnotta, M. A. (2011) HRM technology for the identification and characterization of INDEL and SNP mutations in 
genes involved in drought and salt tolerance of durum wheat. Plant Genet. Resour. 9, 166-169.

Monneveux, P., and Ribaut, J.-M. (2006). "Secondary traits for drought tolerance improvement in cereals," in Drought Adaptation in Cereals, ed J.-M. Ribaut (Binghamton, NY: The Haworth Press, Inc), 97-143

Montes, J., Melchinger, A., and Reif, J. (2007). Novel throughput phenotyping platforms in plant genetic studies. Trends Plant Sci. 12, 433-436.

Morgan, J. W. (1984). Osmoregulation and water stress in higher plants. Annu. Rev. Plant Physiol. 35, 299-319.

Morison, J. I. L., Baker, N. R., Mullineaux, P. M., and Davies, W. J. (2008). Improving water use in crop production. Philos. Trans. $R$. Soc. B Biol. Sci. 363, 639-658.

Munns, R. (1988). Why measure osmotic adjustment? Aust. J. Plant Physiol. 15, 717-726.

Nagy, V., Stekauerova, V., Milics, G., Lichner, L., and Nemenyi, M. (2008). Harmonisation of different measuring methods of soil moisture used in Zitny ostrov (SK) and szigetköz (HU). Cereal Res. Commun. 36(Suppl. 5), 1475-1478.

Nelson, D., Repetti, P., Adams, T., Creelman, R., Wu, J., Warner, D., Anstrom, D., Bensen, R., Castiglioni, P., Donnarummo, M., Hinchey, B., Kumimoto, R., Maszle, D., Canales, R., Krolikowski, K., Dotson, S., Gutterson, N., Ratcliffe, O., and Heard, J. (2007). Plant nuclear factor Y (NF-Y) B subunits confer drought tolerance and lead to improved corn yields on waterlimited acres. Proc. Natl. Acad. Sci. U.S.A. 104, 16450-16455.

Nguyen, H. T., Babu, R. C., and Blum, A. (1997). Breeding for drought resistance in rice: physiology and molecular genetics considerations. Crop Sci. 37, 1426-1434.

Nhan, D. Q., Thaw, S., Matsuo, N., Xuan, T. D., Hong, N. H., and Mochizuki, T. (2006). Evaluation of root penetration ability in rice using the wax-layers and the soil cake methods. J. Fac. Agric. Kyushu Univ. 51, 251-256.

Nissen, T., Rodriguez, V., and Wander, M. (2008). Sampling soybean roots: a comparison of excavation and coring methods. Commun. Soil Sci. Plant Anal. 39, 1875-1883.

Noborio, K. (2001). Measurement of soil water content and electrical conductivity by time domain reflectometry: a review. Comput. Electron. Agric. 31, 213-237.
Norton, G. J., and Price, A. H. (2009). Mapping of quantitative trait loci for seminal root morphology and gravitropic response in rice. Euphytica 166, 229-237.

Ober, E. S., Setter, T. L., Madison, J. T., Thompson, J. F., and Shapiro, P. S. (1991). Influence of water deficit on maize endosperm development: enzyme activities and RNA transcripts of starch and zein synthesis, abscisic acid, and cell division. Plant Physiol. 97, 154-164.

Olivares-Villegas, J. J., Reynolds, M. P., and McDonald, G. K. (2007) Drought-adaptive attributes in the Seri/Babax hexaploid wheat population. Funct. Plant Biol. 34, 189-203.

Ortiz, R., Braun, H. J., Crossa, J., Crouch, J. H., Davenport, G., Dixon, J., Dreisigacker, S., Duveiller, E., He, Z. H., Huerta, J., Joshi, A. K., Kishii, M., Kosina, P., Manes, Y., Mezzalama, M., Morgounov, A., Murakami, J., Nicol, J., Ferrara, G. O., Ortiz-Monasterio, J. I., Payne, T. S., Pena, R. J., Reynolds, M. P., Sayre, K. D., Sharma, R. C., Singh, R. P., Wang, J. K., Warburton, M. Wu, H. X., and Iwanaga, M. (2008). Wheat genetic resources enhancement by the International Maize and Wheat Improvement Center (CIMMYT). Genet. Resour. Crop Evol. 55, 1095-1140.

Ortiz, R., Iwanaga, M., Reynolds, M. P., Wu, H., and Crouch, J. H. (2007a). Overview on crop genetic engineering for drought-prone environments. J. SAT Agric. Res. 4, http://www.icrsat.org/journal/Speci alProject/sp3.pdf.

Ortiz, R., Trethowan, R., Ferrara, G. O. Iwanaga, M., Dodds, J. H., Crouch, J. H., Crossa, J., and Braun, H. J. (2007b). High yield potential, shuttle breeding, genetic diversity, and a new international wheat improvement strategy. Euphytica 157, 365-384.

Palta, J. A., Turner, N. C., French, R. J., and Buirchell, B. J. (2007). Physiological responses of lupin genotypes to terminal drought in a Mediterranean-type environment. Ann. Appl. Biol. 150, 269-279.

Pantuwan, G., Fukai, S., Cooper, M. Rajatasereekul, S., and O'Toole, J. C. (2002). Yield response of rice (Oryza sativa $\mathrm{L}$ ) genotypes to different types of drought under rainfed lowlands - Part 3. Plant factors contributing to drought resistance. Field Crops Res. 73, 181-200.

Passioura, J. B. (1977). Grain yield, harvest index and water use of wheat. J. Aust. Inst. Agric. Sci. 43, 117-120.
Passioura, J. B. (1983). Roots and drought resistance. Agric. Water Manage. 7, 265-280.

Passioura, J. B. (1996). Drought and drought tolerance. Plant Growth Regul. 20, 79-83.

Passioura, J. B. (2002). Environmental biology and crop improvement. Funct. Plant Biol. 29, 537-546.

Passioura, J. B. (2006). The perils of pot experiments. Funct. Plant Biol. 33 , 1075-1079.

Passioura, J. B. (2007). The drought environment: physical, biological and agricultural perspectives. J. Exp. Bot. 58, 113-117.

Passioura, J. B. (2010). Scaling up: the essence of effective agricultural research. Funct. Plant Biol. 37 585-591.

Passioura, J. B., and Angus, J. F. (2010). Improving productivity of crops in water-limited environments. $A d v$ Agron. 106, 37-75.

Patzold, S., Mertens, F. M., Bornemann, L., Koleczek, B., Franke, J. Feilhauer, H., and Welp, G. (2008) Soil heterogeneity at the field scale: a challenge for precision crop protection. Precision Agric. 9 367-390.

Peccoud, J., Vander Velden, K., Podlich, D., Winkler, C., Arthur, L., and Cooper, M. (2004). The selective values of alleles in a molecular network model are context dependent. Genetics 166, 1715-1725.

Pekic, S., Stikic, R., Tomljanovic, L., Andjelkovic, V., Ivanovic, M., and Quarrie, S. A. (1995). Characterization of maize lines differing in leaf abscisic acid content in the field. 1. Abscisic acid physiology. Ann. Bot. 75, 67-73.

Peleg, Z., Fahima, T., and Saranga, Y. (2007). Drought resistance in wild emmer wheat: physiology, ecology, and genetics. Isr. J. Plant Sci. 55 289-296.

Peleg, Z., Saranga, Y., Krugman, T. Abbo, S., Nevo, E., and Fahima, T. (2008). Allelic diversity associated with aridity gradient in wild emmer wheat populations. Plant Cell Environ. 31, 39-49.

Peleman, J. D., and Van der Voort, J. R. (2003). Breeding by design. Trends Plant Sci. 8, 330-334.

Pennisi, E. (2008). The blue revolution, drop by drop, gene by gene. Science 320, 171-173

Pinto, R. S., Reynolds, M. P., Mathews, K. L., McIntyre, C. L., OlivaresVillegas, J. J., and Chapman, S. C. (2010). Heat and drought adaptive QTL in a wheat population designed to minimize confounding agronomic effects. Theor. Appl. Genet. 121, 1001-1021.
Poroyko, V., Spollen, W. G., Hejlek, L. G., Hernandez, A. G., LeNoble, M. E., Davis, G., Nguyen, H. T., Springer, G. K., Sharp, R. E., and Bohnert, H. J. (2007). Comparing regional transcript profiles from maize primary roots under wellwatered and low water potential conditions. J. Exp. Bot. 58, 279-289.

Praba, M. L., Cairns, J. E., Babu, R. C., and Lafitte, H. R. (2009). Identification of physiological traits underlying cultivar differences in drought tolerance in rice and wheat. J. Agron. Crop Sci. 195, 30-46.

Price, A. H., and Tomos, A. D. (1997). Genetic dissection of root growth in rice (Oryza sativa L.). II: mapping quantitative trait loci using molecular markers. Theor. Appl. Genet. 95, 143-152.

Price, A. H., Cairns, J. E., Horton, P., Jones, H. G., and Griffiths, H. (2002a). Linking drought-resistance mechanisms to drought avoidance in upland rice using a QTL approach: progress and new opportunities to integrate stomatal and mesophyll responses. J. Exp. Bot. 53, 989-1004.

Price, A. H., Steele, K. A., Gorham, J., Bridges, J. M., Moore, B. J., Evans, J. L., Richardson, P., and Jones, R. G. W. (2002b). Upland rice grown in soil-filled chambers and exposed to contrasting water-deficit regimes I. Root distribution, water use and plant water status. Field Crops Res. 76, 11-24.

Price, A. H., Steele, K. A., Moore, B. J., and Jones, R. G. W. (2002c). Upland rice grown in soil-filled chambers and exposed to contrasting waterdeficit regimes. II. Mapping quantitative trait loci for root morphology and distribution. Field Crops Res. 76, 25-43.

Price, A. H., Tomos, A. D., and Virk, D. S. (1997a). Genetic dissection of root growth in rice (Oryza sativa L.) I: a hydroponic screen. Theor. Appl. Genet. 95, 132-142.

Price, A. H., Young, E. M., and Tomos, A. D. (1997b). Quantitative trait loci associated with stomatal conductance, leaf rolling and heading date mapped in upland rice (Oryza sativa). New Phytol. 137, 83-91.

Quarrie, S. A. (1991). "Implications of genetic differences in ABA accumulation for crop production," in Abscisic Acid: Physiology and Biochemistry, eds W. J. Davies and H. G. Jones (Oxford, UK: Bios Scientific Publishers), 227-243.

Quarrie, S. A., Whitford, P. N. Appleford, N. E. J., Wang, T. L., Cook, S. K., and Henson, I. E. (1988). A monoclonal antibody to 
(S)-abscisic acid: its characterisation and use in a radioimmunoassay for measuring abscisic acid in crude extracts of cereals and lupin leaves. Planta 173, 330-339.

Rabbani, M. A., Maruyama, K., Abe, H., Khan, M. A., Katsura, K., Ito, Y., Yoshiwara, K., Seki, M., Shinozaki, K., and Yamaguchi-Shinozaki, K. (2003). Monitoring expression profiles of rice genes under cold, drought, and high-salinity stresses and abscisic acid application using cDNA microarray and RNA gelblot analyses. Plant Physiol. 133, 1755-1767.

Rafalski, J. A. (2011). Genomic tools for the analysis of genetic diversity. Plant Genet. Resour. 9, 159-162.

Rahman, H., Pekic, S., Lazic-Jancic, V., Quarrie, S. A., Shah, S. M. A., Pervez, A., and Shah, M. M. (2011). Molecular mapping of quantitative trait loci for drought tolerance in maize plants. Genet. Mol. Res. 10, 889-901.

Rajendran, K., Tester, M., and Roy, S. J. (2009). Quantifying the three main components of salinity tolerance in cereals. Plant Cell Environ. 32, 237-249.

Rascher, U., Blossfeld, S., Fiorani, F., Jahnke, S., Jansen, M., Kuhn, A. J., Matsubara, S., Martin, L. L. A., Merchant, A., Metzner, R., Muller-Linow, M., Nagel, K. A., Pieruschka, R., Pinto, F., Schreiber, C. M., Temperton, V. M., Thorpe, M. R., van Dusschoten, D., van Volkenburgh, E., Windt, C. W., and Schurr, U. (2011). Non-invasive approaches for phenotyping of enhanced performance traits in bean. Funct. Plant Biol. 38, 968-983.

Rauf, S., Sadaqat, H. A., Khan, I. A., and Ahmed, R. (2009). Genetic analysis of leaf hydraulics in sunflower (Helianthus annuus L) under drought stress. Plant Soil Environ. $55,62-69$.

Ravi, K., Vadez, V., Isobe, S., Mir, R. R., Guo, Y., Nigam, S. N., Gowda, M. V. C., Radhakrishnan, T., Bertioli, D. J., Knapp, S. J., and Varshney, R. K. (2011). Identification of several small main-effect QTLs and a large number of epistatic QTLs for drought tolerance related traits in groundnut (Arachis hypogaea L.). Theor. Appl. Genet. 122, 1119-1132.

Rebetzke, G., Condon, A., Farquhar, G., Appels, R., and Richards, R. (2008a). Quantitative trait loci for carbon isotope discrimination are repeatable across environments and wheat mapping populations. Theor. Appl. Genet. 118, 123-137.

Rebetzke, G. J., van Herwaarden, A. F., Jenkins, C., Weiss, M.,
Lewis, D., Ruuska, S., Tabe, L., Fettell, N. A., and Richards, R. A. (2008b). Quantitative trait loci for water-soluble carbohydrates and associations with agronomic traits in wheat. Aust. J. Agric. Res. 59, 891-905.

Rebetzke, G. J., Condon, A. G., Richards, R. A., and Farquhar, G. D. (2002). Selection for reduced carbon isotope discrimination increases aerial biomass and grain yield of rainfed bread wheat. Crop Sci. 42, 739-745.

Rebetzke, G. J., Ellis, M. H., Bonnett, D. G., and Richards, R. A. (2007). Molecular mapping of genes for coleoptile growth in bread wheat (Triticum aestivum L.). Theor. Appl. Genet. 114, 1173-1183.

Ren, H. B., Wei, K. F., Jia, W. S., Davies, W. J., and Zhang, J. H. (2007). Modulation of root signals in relation to stomatal sensitivity to rootsourced abscisic acid in droughtaffected plants. J. Integr. Plant Biol. 49, 1410-1420.

Rensink, W. A. (2005). Microarray expression profiling resources for plant genomics. Trends Plant Sci. 10, 603-609.

Ren, Y., He, X., Liu, D., Li, J., Zhao, X., Li, B., Tong, Y., Zhang, A., and Li, Z. (2012). Major quantitative trait loci for seminal root morphology of wheat seedlings. Mol. Breed. 30, 139-148.

Reshmidevi, T. V., Jana, R., and Eldho, T. I. (2008). Geospatial estimation of soil moisture in rain-fed paddy fields using SCS-CN-based model. Agric. Water Manage. 95, 447-457.

Reymond, M., Muller, B., Leonardi, A., Charcosset, A., and Tardieu, F. (2003). Combining quantitative trait loci analysis and an ecophysiological model to analyze the genetic variability of the responses of maize leaf growth to temperature and water deficit. Plant Physiol. 131, 664-675.

Reymond, M., Muller, B., and Tardieu, F. (2004). Dealing with the genotype $x$ environment interaction via a modelling approach: a comparison of QTLs of maize leaf length or width with QTLs of model parameters. J. Exp. Bot. 55, 2461-2472.

Reynolds, M., Dreccer, F., and Trethowan, R. (2007). Droughtadaptive traits derived from wheat wild relatives and landraces. J. Exp. Bot. 58, 177-186.

Reynolds, M., Manes, Y., Izanloo, A., and Langridge, P. (2009). Phenotyping approaches for physiological breeding and gene discovery in wheat. Ann. Appl. Biol. 155, 309-320.

Reynolds, M., Manes, Y., Izanloo, A. and Langridge, P. (2011). Raising yield potential of wheat. I. Overview of a consortium approach and breeding strategies. J. Exp. Bot. 62, 439-452.

Reynolds, M. P., and Pfeiffer, W. H. (2000). "Applying physiological strategies to improve yield potential," in Durum Wheat Improvement in the Mediterranean Region: New Challenges. Options Mediterranèennes, Vol. 40, eds C. Royo, M. M. Nachit, N. di Fonzo, and J. L. Araus (Zaragozza: CIHEAM), 95-103.

Reynolds, M. P., Mujeeb-Kazi, A., and Sawkins, M. (2005). Prospects for utilising plant-adaptive mechanisms to improve wheat and other crops in drought- and salinityprone environments. Ann. Appl. Biol. 146, 239-259.

Reynolds, M. P., Rajaram, S., and Sayre, K. D. (1999). Physiological and genetic changes of irrigated wheat in the post-green revolution period and approaches for meeting projected global demand. Crop Sci. 39, 1611-1621.

Reynolds, M., and Tuberosa, R. (2008). Translational research impacting on crop productivity in drought-prone environments. Curr. Opin. Plant Biol. 11, 171-179.

Ribaut, J.-M. (ed.). (2006). Drought Adaptation in Cereals. Binghamton, NY, USA: The Haworth Press, Inc. p. 642.

Ribaut, J.-M., Hoisington, D., Banziger, M., Setter, T., and Edmeades, G. (2004). "Genetic dissection of drought tolerance in maize: a case study," in Physiology and Biotechnology Integration for Plant Breeding, eds H. T. Nguyen and A. Blum (New York, USA: Marcel Dekker, Inc.), 571-609.

Ribaut, J.-M., Hoisington, D. A., Deutsch, J. A., Jiang, C., and Gonzalez de Leon, D. (1996). Identification of quantitative trait loci under drought conditions in tropical maize. 1. Flowering parameters and the anthesis-silking interval. Theor. Appl. Genet. 92, 905-914.

Ribaut, J.-M., and Ragot, M. (2007). Marker-assisted selection to improve drought adaptation in maize: the backcross approach, perspectives, limitations, and alternatives. J. Exp. Bot. 58, 351-360.

Richards, R. A. (1991). Crop improvement for temperate Australia: future opportunities. Field Crops Res. 96, 141-169.
Richards, R. A. (1996). Defining selection criteria to improve yield under drought. Plant Growth Regul. 20, 157-166.

Richards, R. A. (2000). Selectable traits to increase crop photosynthesis and yield of grain crops. J. Exp. Bot. 51, 447-458.

Richards, R. A. (2006). Physiological traits used in the breeding of new cultivars for water-scarce environments. Agric. Water Manage. 80, 197-211.

Richards, R. A. (2008). Genetic opportunities to improve cereal root systems for dryland agriculture. Plant Prod. Sci. 11, 12-16.

Richards, R. A., Watt, M., and Rebetzke, G. J. (2007). Physiological traits and cereal germplasm for sustainable agricultural systems. Euphytica 154, 409-425.

Richards, R., Rebetzke, G., Condon, A., and van Herwaarden, A. (2002). Breeding opportunities for increasing the efficiency of water use and crop yield in temperate cereals. Crop Sci. 42, 111-121.

Rossel, R. A. V., Walvoort, D. J. J., McBratney, A. B., Janik, L. J., and Skjemstad, J. O. (2006). Visible, near infrared, mid infrared or combined diffuse reflectance spectroscopy for simultaneous assessment of various soil properties. Geoderma 131, 59-75.

Rostoks, N., Mudie, S., Cardle, L., Russell, J., Ramsay, L., Booth, A., Svensson, J. T., Wanamaker, S. I., Walia, H., Rodriguez, E. M., Hedley, P. E., Liu, H., Morris, J., Close, T. J., Marshall, D. F., and Waugh, R. (2005). Genome-wide SNP discovery and linkage analysis in barley based on genes responsive to abiotic stress. Mol. Genet. Genomics 274, 515-527.

Royo, C., Martos, V., Ramdani, A., Villegas, D., Rharrabti, Y., and del Moral, L. F. G. (2008). Changes in yield and carbon isotope discrimination of Italian and Spanish durum wheat during the 20th century. Agronomy J. 100, 352-360.

Ruta, N., Liedgen, M., Fracheboud, Y., Stamp, P., and Hund, A. (2010). QTLs for the elongation of axile and lateral roots of maize in response to low water potential. Theor. Appl. Genet. 120, 621-631.

Sabadin, P. K., Malosetti, M., Boer, M. P., Tardin, F. D., Santos, F. G., Guimaraes, C. T., Gomide, R. L., Andrade, C. L. T., Albuquerque, P. E. P., Caniato, F. F., Mollinari, M., Margarido, G. R. A., Oliveira, B. F., Schaffert, R. E., Garcia, A. A. F., van Eeuwijk, F. A., and Magalhaes, J. V. (2012). Studying 
the genetic basis of drought tolerance in sorghum by managed stress trials and adjustments for phenological and plant height differences. Theor. Appl. Genet. 124, 1389-1402. Sadok, W., Naudin, P., Boussuge, B., Muller, B., Welcker, C., and Tardieu, F. (2007). Leaf growth rate per unit thermal time follows QTLdependent daily patterns in hundreds of maize lines under naturally fluctuating conditions. Plant Cell Environ. 30, 135-146.

Sadok, W., and Sinclair, T. R. (2011). Crops yield increase under waterlimited conditions: review of recent physiological advances for soybean genetic improvement. Adv. Agron. 113, 313-337.

Sadras, V. (2002). Interaction between rainfall and nitrogen fertilisation of wheat in environments prone to terminal drought: economic and environmental risk analysis. Field Crops Res. 77, 201-215.

Sadras, V. O., Reynolds, M. P., de la Vega, A. J., Petrie, P. R., and Robinson, R. (2009). Phenotypic plasticity of yield and phenology in wheat, sunflower and grapevine. Field Crops Res. 110, 242-250.

Saini, H. S., and Westgate, M. E. (2000). Reproductive development in grain crops during drought. Adv. Agron. 68, 59-96.

Saint Pierre, C., Crossa, J. L., Bonnett, D., Yamaguchi-Shinozaki, K., and Reynolds, M. P. (2012). Phenotyping transgenic wheat for drought resistance. J. Exp. Bot. 63, 1799-1808.

Salekdeh, G. H., Reynolds, M., Bennett, J., and Boyer, J. (2009). Conceptual framework for drought phenotyping during molecular breeding. Trends Plant Sci. 14, 488-496.

Salem, K. F. M., Roder, M. S., and Borner, A. (2007). Identification and mapping quantitative trait loci for stem reserve mobilisation in wheat (Triticum aestivum L.). Cereal Res. Commun. 35, 1367-1374.

Salvi, S., Corneti, S., Bellotti, M., Carraro, N., Sanguineti, M. C., Castelletti, S., and Tuberosa, R. (2011). Genetic dissection of maize phenology using an intraspecific introgression library. BMC Plant Biol. 11, 4

Salvi, S., Sponza, G., Morgante, M., Tomes, D., Niu, X., Fengler, K. A., Meeley, R., Ananiev, E. V., Svitashev, S., Bruggemann, E., Li, B., Hainey, C. F., Radovic, S., Zaina, G., Rafalski, J. A., Tingey, S. V., Miao, G. H., Phillips, R. L., and Tuberosa, R. (2007). Conserved noncoding genomic sequences associated with a flowering-time quantitative trait locus in maize. Proc. Natl. Acad. Sci. U.S.A. 104, 11376-11381.

Salvi, S., and Tuberosa, R. (2007) "Cloning QTLs in plants," in Genomics-Assisted Crop Improvement, Vol 1, Genomics approaches and platforms, eds R. K. Varshney and R. Tuberosa (Dordrecht, The Netherlands: Springer), 207-225.

Salvi, S., Tuberosa, R., Chiapparino, E., Maccaferri, M., Veillet, S., van Beuningen, L., Isaac, P., Edwards, K., and Phillips, R. L. (2002). Toward positional cloning of Vgt 1, a QTL controlling the transition from the vegetative to the reproductive phase in maize. Plant Mol. Biol. 48, 601-613.

Sanguineti, M. C., Duvick, D. N. Smith, S., Landi, P., and Tuberosa R. (2006). Effects of long-term selection on seedling traits and ABA accumulation in commercial maize hybrids. Maydica 51, 329-338.

Sanguineti, M. C., Giuliani, M. M. Govi, G., Tuberosa, R., and Landi, P. (1998). Root and shoot traits of maize inbred lines grown in the field and in hydroponic culture and their relationships with root lodging. Maydica 43, 211-216.

Sanguineti, M. C., Li, S., Maccaferri, M., Corneti, S., Rotondo, F., Chiari, T., and Tuberosa, R. (2007). Genetic dissection of seminal root architecture in elite durum wheat germplasm. Ann. Appl. Biol. 151, 291-305.

Sanguineti, M. C., Tuberosa, R., Landi, P., Salvi, S., Maccaferri, M., Casarini, E., and Conti, S. (1999). QTL analysis of drought related traits and grain yield in relation to genetic variation for leaf abscisic acid concentration in field-grown maize. J. Exp. Bot. 50, 1289-1297.

Saranga, Y., Menz, M., Jiang, C. X. Wright, R. J., Yakir, D., and Paterson, A. H. (2001). Genomic dissection of genotype $x$ environment interactions conferring adaptation of cotton to arid conditions. Genome Res. 11, 1988-1995.

Sawkins, M. C., Farmer, A. D. Hoisington, D., Sullivan, J., Tolopko, A., Jiang, Z., and Ribaut, J.-M. (2004). Comparative Map and Trait Viewer (CMTV): an integrated bioinformatic tool to construct consensus maps and compare QTL and functional genomics data across genomes and experiments. Plant Mol. Biol. 56, 465-480.

Seiler, C., Harshavardhan, V. T., Rajesh, K., Reddy, P. S., Strickert, M., Rolletschek, H., Scholz, U., Wobus, U., and Sreenivasulu, N. (2011). ABA biosynthesis and degradation contributing to ABA homeostasis during barley seed development under control and terminal drought-stress conditions. J. Exp. Bot. 62, 2615-2632.

Seki, M., Umezawa, T., Urano, K., and Shinozaki, K. (2007). Regulatory metabolic networks in drought stress responses. Curr. Opin. Plant Biol. 10, 296-302.

Serraj, R., McNally, K. L., SlametLoedin, I., Kohli, A., Haefele, S. M. Atlin, G., and Kumar, A. (2011) Drought resistance improvement in rice: an integrated genetic and resource management strategy. Plant Prod. Sci. 14, 1-14.

Serraj, R., and Sinclair, T. R. (2002). Osmolyte accumulation: can it really help increase crop yield under drought conditions? Plant Cell Environ. 25, 333-341.

Setter, T. L. (2006). "The role of abscisic acid under water-limited conditions," in Drought Adaptation in Cereals, ed J.-M. Ribaut (Binghamton, NY, USA: The Haworth Press, Inc.), 505-530.

Setter, T. L., Flannigan, B. A., and Melkonian, J. (2001). Loss of kernel set due to water deficit and shade in maize: carbohydrate supplies, abscisic acid, and cytokinins. Crop Sci. 41, 1530-1540.

Setter, T. L., Mambelli, S., Flannigan, B. A., and Kim, S. E. (1996). Wate deficit inhibition of cell division in apical-kernel endosperms of maize: $\mathrm{ABA}$ and sugar responses. Plant Physiol. 111, 225-225.

Sharp, R. E. (2002). Interaction with ethylene: changing views on the role of abscisic acid in root and shoot growth responses to water stress. Plant Cell Environ. 25, 211-222.

Sharp, R. E., Poroyko, V., Hejlek, L. G., Spollen, W. G., Springer, G. K., Bohnert, H. J., and Nguyen, H. T. (2004). Root growth maintenance during water deficits: physiology to functional genomics. J. Exp. Bot. 55, 2343-2351.

Shukla, A. K., Ladha, J. K., Singh, V. K., Dwivedi, B. S., Balasubramanian, V., Gupta, R. K., Sharma, S. K. Singh, Y., Pathak, H., Pandey, P. S., Padre, A. T., and Yadav, R. L. (2004) Calibrating the leaf color chart for nitrogen management in different genotype of rice and wheat in a systems perspective. Agron. J. 96, 1606-1621.

Sinclair, T. R. (2011). Challenges in breeding for yield increase for drought. Trends Plant Sci. 16, 289-293.

Sinclair, T. R., Messina, C. D., Beatty, A. and Samples, M. (2010). Assessment across the United States of the benefits of altered soybean drought traits. Agron. J. 102, 475-482.

Sinclair, T. R., and Purcell, L. C. (2005). Is a physiological perspective relevant in a 'genocentric' age? J. Exp. Bot. 56, 2777-2782.

Sinclair, T. R., Purcell, L. C., King, C. A., Sneller, C. H., Chen, P. Y., and Vadez, V. (2007). Drought tolerance and yield increase of soybean resulting from improved symbiotic $\mathrm{N}-2$ fixation. Plant Genet. Resour. 101, 68-71.

Sinclair, T. R., Purcell, L. C., and Sneller, C. H. (2004). Crop transformation and the challenge to increase yield potential. Trends Plant Sci. 9, 70-75.

Sinclair, T. R., Zwieniecki, M. A., and Holbrook, N. M. (2008). Low leaf hydraulic conductance associated with drought tolerance in soybean. Physiol. Plant. 132, 446-451.

Singh, V., van Oosterom, E. J., Jordan, D. R., Hunt, C. H., and Hammer, G. L. (2011). Genetic variability and control of nodal root angle in sorghum. Crop Sci. 51, 2011-2020.

Siopongco, J., Sekiya, K., Yamauchi, A., Egdane, J., Ismail, A. M., and Wade, L. J. (2008). Stomatal responses in rainfed lowland rice to partial soil drying; evidence for root signals. Plant Prod. Sci. 11, 28-41.

Siopongco, J., Sekiya, K., Yamauchi, A. Egdane, J., Ismail, A. M., and Wade, L. J. (2009). Stomatal responses in rainfed lowland rice to partial soil drying; comparison of two lines. Plant Prod. Sci. 12, 17-28.

Sirichandra, C., Wasilewska, A., Vlad, F., Valon, C., and Leung, J. (2009). The guard cell as a single-cell model towards understanding drought tolerance and abscisic acid action. J. Exp. Bot. 60, 1439-1463.

Slafer, G. A., Araus, J. L., Royo, C., and Garcia Del Moral, L. F. (2005). Promising eco-physiological traits for genetic improvement of cereal yields in Mediterranean environments. Ann. Appl. Biol. 146, 61-70.

Smit, A. L., and Groenwold, J. (2005). Root characteristics of selected field crops: data from the Wageningen Rhizolab (1990-2002). Plant Soil 272, 365-384.

Snape, J. W., Foulkes, M. J., Simmonds, J., Leverington, M., Fish, L. J., Wang, Y., and Ciavarrella, M. (2007). Dissecting gene $\times$ environmental effects on wheat yields via QTL and physiological analysis. Euphytica 154, 401-408.

Soltani, A., and Sinclair, T. R. (2012). Optimizing chickpea phenology to available water under current and future climates. Eur. J. Agron. 38, 22-31. 
Spielmeyer, W., Hyles, J., Joaquim, P., Azanza, F., Bonnett, D., Ellis, M. E., Moore, C., and Richards, R. A. (2007). A QTL on chromosome 6A in bread wheat (Triticum aestivum) is associated with longer coleoptiles, greater seedling vigour and final plant height. Theor. Appl. Genet. 115, 59-66.

Spollen, W. G., LeNoble, M. E., Samuels, T. D., Bernstein, N., and Sharp, R. E. (2000). Abscisic acid accumulation maintains maize primary root elongation at low water potentials by restricting ethylene production. Plant Physiol. 122, 967-976.

Sreenivasulu, N., Sunkar, R., Wobus, U., and Strickert, M. (2010). Array platforms and bioinformatics tools for the analysis of plant transcriptome in response to abiotic stress. Methods Mol. Biol. 639, 71-93.

Steele, K. A., Price, A. H., Shashidhar, H. E., and Witcombe, J. R. (2006). Marker-assisted selection to introgress rice QTLs controlling root traits into an Indian upland rice variety. Theor. Appl. Genet. 112, 208-221.

Steele, K. A., Virk, D. S., Kumar, R., Prasad, S. C., and Witcombe, J. R. (2007). Field evaluation of upland rice lines selected for QTLs controlling root traits. Field Crops Res. 101, 180-186.

Subashri, M., Robin, S., Vinod, K. K., Rajeswari, S., Mohanasundaram, K., and Raveendran, T. S. (2009). Trait identification and QTL validation for reproductive stage drought resistance in rice using selective genotyping of near flowering RILs. Euphytica 166, 291-305.

Swaminathan, M. S. (2005). "Towards an ever-green revolution," in Proceedings of the International Congress: In the Wake of the Double Helix: From the Green Revolution to the Gene Revolution, 27-31 May 2003, Bologna, Italy eds R. Tuberosa, R. L. Phillips, and M. Gale (Bologna, Italy: Avenue Media), 25-36.

Takai, T., Fukuta, Y., Sugimoto, A., Shiraiwa, T., and Horie, T. (2006). Mapping of QTLs controlling carbon isotope discrimination in the photosynthetic system using recombinant inbred lines derived from a cross between two different rice (Oryza sativa L.) cultivars. Plant Prod. Sci. 9, 271-280.

Talamè, V., Ozturk, N. Z., Bohnert, H. J., and Tuberosa, R. (2007). Barley transcript profiles under dehydration shock and drought stress treatments: a comparative analysis. J. Exp. Bot. 58, 229-240.
Talamè, V., Sanguineti, M. C., Chiapparino, E., Bahri, H., Ben Salem, M., Forster, B. P., Ellis, R. P., Rhouma, S., Zoumarou, W., Waugh, R., and Tuberosa, R. (2004). Identification of Hordeum spontaneum QTL alleles improving field performance of barley grown under rainfed conditions. Ann. Appl. Biol. 144, 309-319.

Tambussi, E. A., Bort, J., and Araus, J. L. (2007). Water use efficiency in C3 cereals under Mediterranean conditions: a review of physiological aspects. Ann. Appl. Biol. 150, 307-321.

Tan, L. B., Zhang, P. J., Liu, F. X., Wang, G. J., Ye, S., Zhu, Z. F., Fu, Y. C., Cai, H. W., and Sun, C. Q. (2008). Quantitative trait loci underlying domestication and yield-related traits in an Oryza sativa $\times$ Oryza rufipogon advanced backcross population. Genome 51, 692-704.

Tangpremsri, T., Fukai, S., and Fischer, K. S. (1995). Growth and yield of sorghum lines extracted from a population for differences in osmotic adjustment. Aust. J. Agric. Res. 46, 61-74.

Tang, R. S., Zheng, J. C., Jin, Z. Q., Zhang, D., Huang, H., and Chen, L. G. (2008). Possible correlation between high temperature-induced floret sterility and endogenous levels of IAA, GAs and ABA in rice (Oryza sativa L.). Plant Growth Regul. 54, 37-43.

Tanksley, S. D., and McCouch, S. R. (1997). Seed banks and molecular maps: unlocking genetic potential from the wild. Science 277, 1063-1066.

Tardieu, F. (2003). Virtual plants: modelling as a tool for the genomics of tolerance to water deficit. Trends Plant Sci. 8, 9-14.

Tardieu, F. (2012). Any trait or traitrelated allele can confer drought tolerance: just design the right drought scenario. J. Exp. Bot. 63, 25-31.

Tardieu, F., Muller, B., and Reymond, M. (2003). Leaf growth regulation under drought: combining ecophysiological modelling, QTL analysis and search for mechanisms. J. Exp. Bot. 54, 18-19.

Tardieu, F., Reymond, M., Muller, B., Granier, C., Simonneau, T., Sadok, W., and Welcker, C. (2005). Linking physiological and genetic analyses of the control of leaf growth under changing environmental conditions. Aust. J. Agric. Res. 56, 937-946.

Tardieu, F., and Tuberosa, R. (2010). Dissection and modelling of abiotic stress tolerance in plants. Curr. Opin. Plant Biol. 13, 206-212.

Tester, M., and Langridge, P. (2010). Breeding technologies to increase crop production in a changing world. Science 327, 818-822.

Texeira, L. R., Braccini, A. D. E., Sperandio, D., Scapim, C. A., Schuster, I., and Vigano, J. (2008). Evaluation of soybean cultivars regarding tolerance to water stress in substrate containing polyethylene glycol. Acta Sci. Agron. 30, 217-223.

Thomas, H., and Howarth, C. J. (2000). Five ways to stay green. J. Exp. Bot. 51, 329-337.

Thompson, A. J., Andrews, J., Mulholland, B. J., McKee, J. M. T., Hilton, H. W., Black, C. R., and Taylor, I. B. (2007). Overproduction of abscisic acid in tomato increases transpiration efficiency and root hydraulic conductivity and influences leaf expansion. Plant Physiol. 143, 1905-1917.

Timperio, A. M., Egidi, M. G., and Zolla, L. (2008). Proteomics applied on plant abiotic stresses: role of heat shock proteins (HSP). J. Proteomics 71, 391-411.

Tollenaar, M., and Lee, E. A. (2006). Dissection of physiological processes underlying grain yield in maize by examining genetic improvement and heterosis. Maydica 51, 399-408.

Tollenaar, M., and Wu, J. (1999). Yield improvement in temperate maize is attributable to greater stress tolerance. Crop Sci. 39, 1597-1604.

Trachsel, S., Kaeppler, S. M., Brown, K. M., and Lynch, J. P. (2011). Shovelomics: high throughput phenotyping of maize (Zea mays L.) root architecture in the field. Plant Soil 341, 75-87.

Tracy, S. R., Roberts, J. A., Black, C. R., McNeill, A., Davidson, R., and Mooney, S. J. (2010). The X-factor: visualizing undisturbed root architecture in soils using X-ray computed tomography. J. Exp. Bot. 61, 311-313.

Trebbi, D., Maccaferri, M., de Heer, P., Sorensen, A., Giuliani, S., Salvi, S., Sanguineti, M. C., Massi, A., van der Vossen, E. A. G., and Tuberosa, R. (2011). High-throughput SNP discovery and genotyping in durum wheat (Triticum durum Desf.). Theor. Appl. Genet. 123, 555-569.

Trethowan, R., and Crossa, J. (2007). Lessons learnt from forty years of international spring bread wheat trials. Euphytica 157, 385-390.

Tuberosa, R. (2004). "Molecular approaches to unravel the genetic basis of water use efficiency," in
Water Use Efficiency in Plant Biology, ed M. A. Bacon (Oxford, UK: Blackwell Publishing), 228-301.

Tuberosa, R., Giuliani, S., Parry, M. A. J., and Araus, J. L. (2007a). Improving water use efficiency in Mediterranean agriculture: what limits the adoption of new technologies? Ann. Appl. Biol. 150, 157-162.

Tuberosa, R., Salvi, S., Giuliani, S., Sanguineti, M. C., Bellotti, M., Conti, S., and Landi, P. (2007b). Genome-wide approaches to investigate and improve maize response to drought. Crop Sci. 47, S-120-S-141.

Tuberosa, R., Graner, A., and Varshney, R. K. (2011a). Genomics of plant genetic resources: an introduction. Plant Genet. Resour. 9, 151-154.

Tuberosa, R., Salvi, S., Giuliani, S., Sanguineti, M. C., Frascaroli, E., Conti S., and Landi, P. (2011b). "Genomics of root architecture and functions in maize," in Root genomics eds A. Costa de Oliveira and R. K. Varshney (Dordrecht, The Netherlands: Springer), 179-204.

Tuberosa, R., and Salvi, S. (2006). Genomics-based approaches to improve drought tolerance of crops. Trends Plant Sci. 11, 405-412.

Tuberosa, R., Salvi, S., Sanguineti, M. C., Landi, P., Maccaferri, M., and Conti, S. (2002a). Mapping QTLs regulating morpho-physiological traits and yield: case studies, shortcomings and perspectives in drought-stressed maize. Ann. Bot. 89, 941-963.

Tuberosa, R., Sanguineti, M. C., Landi, P., Giuliani, M. M., Salvi, S., and Conti, S. (2002b). Identification of QTLs for root characteristics in maize grown in hydroponics and analysis of their overlap with QTLs for grain yield in the field at two water regimes. Plant Mol. Biol. 48, 697-712.

Tuberosa, R., Salvi, S., Sanguineti, M. C., Maccaferri, M., Giuliani, S., and Landi, P. (2003). Searching for quantitative trait loci controlling root traits in maize: a critical appraisal. Plant Soil 255, 35-54.

Tuberosa, R., Sanguineti, M. C., and Landi, P. (1994). Abscisic acid concentration in the leaf and xylem sap, leaf water potential, and stomatal conductance in drought-stressed maize. Crop Sci. 34, 1557-1563.

Tuberosa, R., Sanguineti, M. C., Landi, P., Salvi, S., Casarini, E., and Conti, S. (1998). RFLP mapping of quantitative trait loci controlling abscisic acid concentration in leaves of drought-stressed maize (Zea mays L.). Theor. Appl. Genet. 97, 744-755. 
Tuberosa, R., Sanguineti, M. C., Stefanelli, S., and Quarrie, S. A. (1992). Number of endosperm cells and weight of barley kernels in relation to endosperm abscisic acid content. Eur. J. Agron. 1, 125-132.

Tuinstra, M. R., Ejeta, G., and Goldsbrough, P. (1998). Evaluation of near-isogenic sorghum lines contrasting for QTL markers associated with drought tolerance. Crop Sci. 38, 835-842.

Turner, N. C. (1997). Further progress in crop water relations. Adv. Agron. 528, 293-338.

Turner, N. C., Palta, J. A., Shrestha, R., Ludwig, C., Siddique, K. H. M., and Turner, D. W. (2007). Carbon isotope discrimination is not correlated with transpiration efficiency in three cool-season grain legumes (Pulses). J. Integr. Plant Biol. 49, 1478-1483.

Ulloa, M., Cantrell, R. G., Percy, R. G., Zeiger, E., and Lu, Z. M. (2000). QTL analysis of stomatal conductance and relationship to lint yield in an interspecific cotton. J. Cotton Sci. 4, 10-18.

Umezawa, T., Fujita, M., Fujita, Y., Yamaguchi-Shinozaki, K., and Shinozaki, K. (2006). Engineering drought tolerance in plants: discovering and tailoring genes to unlock the future. Curr. Opin. Biotechnol. 17, 113-122.

Vadez, V., Deshpande, S. P., Kholova, J., Hammer, G. L., Borrell, A. K., Talwar, H. S., and Hash, C. T. (2011). Stay-green quantitative trait loci's effects on water extraction, transpiration efficiency and seed yield depend on recipient parent background. Funct. Plant Biol. 38, 553-566.

van Beem, J., Smith, M. E., and Zobel, R. W. (1998). Estimating root mass in maize using a portable capacitance meter. Agron. J. 90, 566-570.

van Eeuwijk, F. (2006). "Genotype by environment interaction-basics and beyond," in Plant Breeding: The Arnel, R. Hallauer International Symposium, eds K. R. Lamkey and M. Lee (Ames, IA, USA: Blackwell Publishing), 155-170.

van Eeuwijk, F. A., Malosetti, M., Yin, X. Y., Struik, P. C., and Stam, P. (2005). Statistical models for genotype by environment data: from conventional ANOVA models to eco-physiological QTL models. Aust. J. Agric. Res. 56, 883-894.

van Ginkel M., and Ogbonnaya, F. (2007). Novel genetic diversity from synthetic wheats in breeding cultivars for changing production conditions. Field Crops Res. 104, 86-94.
Vargas, M., van Eeuwijk, F. A., Crossa, J., and Ribaut, J.-M. (2006). Mapping QTLs and QTL $\times$ environment interaction for CIMMYT maize drought stress program using factorial regression and partial least squares methods. Theor. Appl. Genet. 112, 1009-1023.

Varshney, R. K., Nayak, S. N., May, G. D., and Jackson, S. A. (2009). Next-generation sequencing technologies and their implications for crop genetics and breeding. Trends Biotechnol. 27, 522-530.

Varshney, R. K., Paulo, M. J., Grando, S., van Eeuwijk, F. A., Keizer, L. C. P., Guo, P., Ceccarelli, S., Kilian, A., Baum, M., and Graner, A. (2012). Genome wide association analyses for drought tolerance related traits in barley (Hordeum vulgare L.) Plant Genet. Resour. 126, 171-180.

Varshney, R. K., Pazhamala, L., Kashiwagi, J., Gaur, P. M., Krishnamurthy, L., and Hoisington, D. (2011). "Genomics and physiological approaches for root trait breeding to improve drought tolerance in chickpea (Cicer arietinum L.)," in Root genomics eds A. Costa de Oliveira and R. K. Varshney (Dordrecht, The Netherlands: Springer), 233-250.

Venuprasad, R., Bool, M. E., Dalid, C. O., Bernier, J., Kumar, A., and Atlin G. N. (2009a). Genetic loci responding to two cycles of divergent selection for grain yield under drought stress in a rice breeding population. Euphytica 167, 261-269.

Venuprasad, R., Dalid, C. O., Del Valle, M., Zhao, D., Espiritu, M., Cruz, M. T. S., Amante, M., Kumar, A., and Atlin, G. N. (2009b). Identification and characterization of largeeffect quantitative trait loci for grain yield under lowland drought stress in rice using bulk-segregant analysis. Theor. Appl. Genet. 120 177-190.

Venuprasad, R., Bool, M. E., Quiatchon, L., and Atlin, G. N. (2012). A QTL for rice grain yield in aerobic environments with large effects in three genetic backgrounds. Theor. Appl. Genet. 124, 323-332.

Vereecken, H., Huisman, J. A., Bogena, H., Vanderborght, J., Vrugt, J. A., and Hopmans, J. W. (2008). On the value of soil moisture measurements in vadose zone hydrology: a review. Water Resour. Res. 44, 21.

Verslues, P. E., Agarwal, M., KatiyarAgarwal, S., Zhu, J. H., and Zhu, J. K. (2006). Methods and concepts in quantifying resistance to drought, salt and freezing, abiotic stresses that affect plant water status. Plant J. 45, 523-539.
Vij, S., and Tyagi, A. K. (2007). Emerging trends in the functional genomics of the abiotic stress response in crop plants. Plant Biotechnol. J. 5, 361-380.

Vikram, P., Swamy, B. P. M., Dixit, S., Ahmed, H. U., Sta Cruz, M. T., Singh, A. K., and Kumar, A. (2011). qDTY(1.1), a major QTL for rice grain yield under reproductivestage drought stress with a consistent effect in multiple elite genetic backgrounds. BMC Genet. 12, 89 .

Wade, L. J., Kamoshita, A., Yamauchi, A., and Azhiri-Sigari, T. (2000) Genotypic variation in response of rainfed lowland rice to drought and rewatering. I. Growth and water use. Plant Prod. Sci. 3, 173-179.

Wasilewska, A., Vlad, F., Sirichandra, C., Redko, Y., Jammes, F., Valon, C. Frey, N. F. D., and Leung, J. (2008). An update on abscisic acid signaling in plants and more. Mol. Plant 1, 198-217.

Wasson, A. P., Richards, R. A., Chatrath, R., Misra, S. C., Prasad, S. V. S., Rebetzke, G. J., Kirkegaard, J. A., Christopher J., and Watt, M (2012). Traits and selection strategies to improve root systems and water uptake in water-limited wheat crops. J. Exp. Bot. 63, 3485-3498.

Waugh, R., Jannink, J. L., Muehlbauer, G. J., and Ramsay, L. (2009). The emergence of whole genome association scans in barley. Curr. Opin. Plant Biol. 12, 218-222.

Welcker, C., Boussuge, B., Bencivenni, C., Ribaut, J.-M., and Tardieu, F. (2007). Are source and sink strengths genetically linked in maize plants subjected to water deficit? A QTL study of the responses of leaf growth and of Anthesis-Silking Interval to water deficit. J. Exp. Bot. 58, 339-349.

Welcker, C., Sadok, W., Dignat, G., Renault, M., Salvi, S., Charcosset, A., and Tardieu, F. (2011). A common genetic determinism for sensitivities to soil water deficit and evaporative demand: metaanalysis of quantitative trait loci and introgression lines of maize. Plant Physiol. 157, 718-729.

Werban, U., al Hagrey, S. A., and Rabbel, W. (2008). Monitoring of root-zone water content in the laboratory by $2 \mathrm{D}$ geoelectrical tomography. J. Plant Nutr. Soil Sci. 171, 927-935.

White, J. W., Andrade-Sanchez, P. Gore, M. A., Bronson, K. F., Coffelt, T. A., Conley, M. M., Feldmann, K. A., French, A. N., Heun, J. T., Hunsaker, D. J., Jenks, M. A. Kimball, B. A., Roth, R. L., Strand, R. J., Thorp, K. R., Wall, G. W. and Wang, G. Y. (2012). Fieldbased phenomics for plant genetics research. Field Crops Res. 133, 101-112.

Winterhalter, L., Mistele, B., Jampatong, S., and Schmidhalter, U. (2011a). High throughput phenotyping of canopy water mass and canopy temperature in well-watered and drought stressed tropical maize hybrids in the vegetative stage. Eur. J. Agron. 35, 22-32.

Winterhalter, L., Mistele, B., Jampatong, S., and Schmidhalter, U. (2011b). High-throughput sensing of aerial biomass and above-ground nitrogen uptake in the vegetative stage of well-watered and drought stressed tropical maize hybrids. Crop Sci. 51, 479-489.

Witcombe, J. R., Hollington, P. A., Howarth, C. J., Reader, S., and Steele, K. A. (2008). Breeding for abiotic stresses for sustainable agriculture. Philos. Trans. R. Soc. B Biol. Sci. 363, 703-716.

Xiong, Y. C., Li, F. M., Zhang, T., and Xia, C. (2007). Evolution mechanism of non-hydraulic root-to-shoot signal during the anti-drought genetic breeding of spring wheat. Environ. Exp. Bot. 59, 193-205.

Xu, X., Yuan, H., Li, S., and Monneveux, P. (2007). Relationship between carbon isotope discrimination and grain yield in spring wheat under different water regimes and under saline conditions in the Ningxia Province (North-west China). J. Agron. Crop Sci. 193 422-434.

Xu, Y. B., and Crouch, J. H. (2008). Marker-assisted selection in plant breeding: from publications to practice. Crop Sci. 48, 391-407.

Yadav, R. S., Sehgal, D., and Vadez, V. (2011). Using genetic mapping and genomics approaches in understanding and improving drought tolerance in pearl millet. J. Exp. Bot. 62, 397-408

Yang, J. C., Zhang, J. H., Liu, K., Wang, Z. Q., and Liu, L. J. (2007). Abscisic acid and ethylene interact in rice spikelets in response to water stress during meiosis. J. Plant Growth Regul. 26, 318-328.

Yang, S. J., Vanderbeld, B., Wan, J. X., and Huang, Y. F. (2010). Narrowing down the targets: towards successful genetic engineering of drought-tolerant crops. Mol. Plant 3, 469-490.

Yang, Z., Sinclair, T. R., Zhu, M., Messina, C. D., Cooper, M., and Hammer, G. L. (2012). Temperature effect on transpiration response 
of maize plants to vapour pressure deficit. Environ. Exp. Bot. 78, 157-162.

Yin, X., and Struik, P. C. (2008). Applying modelling experiences from the past to shape crop systems biology: the need to converge crop physiology and functional genomics. New Phytol. 179, 629-642.

Yin, X., Struik, P. C., and Kropff, M. J. (2004). Role of crop physiology in predicting gene-to-phenotype relationships. Trends Plant Sci. 9, 426-432.

Yin, X. Y., Stam, P., Kropff, M. J., and Schapendonk, A. H. C. M. (2003). Crop modeling, QTL mapping, and their complementary role in plant breeding. Agron. J. 95, 90-98.

Yin, X. Y., Struik, P. C., van Eeuwijk, F. A., Stam, P., and Tang, J. J. (2005). QTL analysis and QTLbased prediction of flowering phenology in recombinant inbred lines of barley. J. Exp. Bot. 56, 967-976.

Yu, G. R., Zhuang, J., Nakayama, K., and Jin, Y. (2007). Root water uptake and profile soil water as affected by vertical root distribution. Plant Ecol. 189, 15-30.

Yue, B., Xue, W. Y., Xiong, L. Z., Yu, X. Q., Luo, L. J., Cui, K. H., Jin,
D. M., Xing, Y. Z., and Zhang, Q. F. (2006). Genetic basis of drought resistance at reproductive stage in rice: separation of drought tolerance from drought avoidance. Genetics 172, 1213-1228.

Zaman-Allah, M., Jenkinson, D. M., and Vadez, V. (2011a). A conservative pattern of water use, rather than deep or profuse rooting, is critical for the terminal drought tolerance of chickpea. J. Exp. Bot. 62, 4239-4252.

Zaman-Allah, M., Jenkinson, D. M., and Vadez, V. (2011b). Chickpea genotypes contrasting for seed yield under terminal drought stress in the field differ for traits related to the control of water use. Funct. Plant Biol. 38, 270-281.

Zhang, H., Tan, G. L. L., Yang, L. N. N., Yang, J. C., Zhang, J. H., and Zhao, B. H. (2009). Hormones in the grains and roots in relation to post-anthesis development of inferior and superior spikelets in japonica/indica hybrid rice. Plant Physiol. Biochem. 47, 195-204.

Zhang, J., and Davies, W. J. (1990). Does ABA in the xylem control the rate of leaf growth in soil dried maize and sunflower plants? J. Exp. Bot. 41, 1125-1132.
Zhang, J. X., Nguyen, H. T., and Blum, A. (1999). Genetic analysis of osmotic adjustment in crop plants. J. Exp. Bot. 50, 291-302.

Zhao, X. Q., Xu, J. L., Zhao, M., Lafitte, R., Zhu, L. H., Fu, B. Y., Gao, Y. M. and $\mathrm{Li}, \mathrm{Z}$. K. (2008). QTLs affecting morpho-physiological traits related to drought tolerance detected in overlapping introgression lines of rice (Oryza sativa L.). Plant Sci. 174, 618-625.

Zheng, B. Y., Shi, L. J., Ma, Y. T., Deng, Q. Y., Li, B. G., and Guo, Y. (2008). Comparison of architecture among different cultivars of hybrid rice using a spatial light model based on 3-D digitising. Funct. Plant Biol. 35, 900-910.

Zheng, H. J., Wu, A. Z., Zheng, C. C., Wang, Y. F., Cai, R., Shen, X. F., $\mathrm{Xu}$, R. R., Liu, P., Kong, L. J., and Dong, S. T. (2009). QTL mapping of maize (Zea mays) stay-green traits and their relationship to yield. Plant Breed. 128, 54-62.

Zhu, J., Ingram, P. A., Benfey, P. N., and Elich, T. (2011). From lab to field, new approaches to phenotyping root system architecture. Curr. Opin. Plant Biol. 14, 310-317.

Zhu, J. M., Mickelson, S. M., Kaeppler, S. M., and Lynch, J. P. (2006)
Detection of quantitative trait loci for seminal root traits in maize ( $\mathrm{Zea}$ mays L.) seedlings grown under differential phosphorus levels. Theor. Appl. Genet. 113, 1-10.

Conflict of Interest Statement: The author declares that the research was conducted in the absence of any commercial or financial relationships that could be construed as a potential conflict of interest.

Received: 01 May 2012; accepted: 09 August 2012; published online: 19 September 2012.

Citation: Tuberosa $R \quad$ (2012) Phenotyping for drought tolerance of crops in the genomics era. Front. Physio. 3:347. doi: 10.3389/fphys. 2012.00347

This article was submitted to Frontiers in Plant Physiology, a specialty of Frontiers in Physiology.

Copyright (c) 2012 Tuberosa. This is an open-access article distributed under the terms of the Creative Commons Attribution License, which permits use, distribution and reproduction in other forums, provided the original authors and source are credited and subject to any copyright notices concerning any thirdparty graphics etc. 